\title{
Quantum Dots and Nanowires Grown by Metal-Organic Chemical Vapor Deposition for Optoelectronic Device Applications
}

\author{
H. H. Tan, Senior Member, IEEE, K. Sears, Student Member, IEEE, S. Mokkapati, Student Member, IEEE, \\ Lan Fu, Member, IEEE, Yong Kim, P. McGowan, Member, IEEE, M. Buda, and Chennupati Jagadish, Fellow, IEEE
}

(Invited Paper)

\begin{abstract}
This paper discusses the growth of $\operatorname{In}(\mathrm{Ga})$ As quantum dots (QDs) and nanowires by metal-organic chemical vapor deposition and their application to optoelectronic devices. The performance characteristics of QD lasers and QD photodetectors as well as the selective area growth of QDs for integrated devices are reported.
\end{abstract}

Index Terms-Integrated optoelectronics, nanowires, photodetectors, quantum dots, semiconductor lasers.

\section{INTRODUCTION}

$\mathbf{N}$ ANOSIZED structures such as quantum dots (QDs) and nanowires are exciting due to their increased carrier confinement and potential for improved and novel optoelectronic devices. Two QD applications that have gained a lot of attention are the QD laser and the photodetector. Compared to their quantum well $(\mathrm{QW})$ counterparts, reduced threshold currents, increased differential efficiency, and high-temperature characteristics are predicted for QD lasers, while high sensitivity to normal incident infrared radiation, lower dark current, and higher responsivity and detectivity are predicted for QD photodetectors. While many of these characteristics are routinely demonstrated for QD devices grown by molecular beam epitaxy (MBE) [1], [2], this is not generally the case for QD devices grown by metal-organic chemical vapor deposition (MOCVD) [3], [4] despite its importance in industry. In this paper, we report the growth of $\operatorname{In}(\mathrm{Ga})$ As QDs via the Stranski-Krastanow (SK) growth mode by MOCVD, and their application to QD lasers and infrared photodetectors. Selective area epitaxy (SAE) method,

Manuscript received March 1, 2006; revised July 2, 2006. This work was supported by the Australian Research Council.

H. H. Tan, K. Sears, S. Mokkapati, L. Fu, and C. Jagadish are with the Department of Electronic Materials Engineering, Research School of Physical Sciences and Engineering, The Australian National University, Canberra ACT 0200, Australia (e-mail: hoe109@rsphysse.anu.edu.au; kks109@rsphysse.anu.edu.au; fu1109@rsphysse.anu.edu.au; c.jagadish@ieee.org).

Y. Kim is with the Department of Electronic Materials Engineering, Research School of Physical Sciences and Engineering, The Australian National University, Canberra ACT 0200, Australia, and also with the Department of Physics, Dong-A University, Busan 604-714, Korea.

P. McGowan is with TTPcom Ltd., Cambridge SG8 6HQ, U.K.

M. Buda is with the Department of Electronic Materials Engineering, Research School of Physical Sciences and Engineering, The Australian National University, Canberra ACT 0200, Australia, and also with the National Institute of Material Physics, Bucharest 77125, Romania (e-mail: bmn109@rsphysse.anu.edu.au).

Digital Object Identifier 10.1109/JSTQE.2006.882663 which is promising for device integration, is also demonstrated. The growth of nanowires via the vapor-liquid-solid (VLS) mechanism is also of great interest because it enables the flexible growth of nanoscale devices such as nanowire lasers [5], resonant tunneling diodes [6], and single-electron tunneling diodes [7], without the strain issues associated with bulk and QD growth. In this paper, growth of different nanowire structures is demonstrated, which could lead to novel device applications.

\section{EXPERIMENTAL DETAILS}

A low-pressure (100 mbar), AIXTRON 200/4, horizontalflow MOCVD reactor was used to grow all the samples and devices discussed in this paper. The standard precursor sources, trimethylindium (TMIn), trimethylgallium (TMGa), trimethylaluminum (TMAl), and $\mathrm{AsH}_{3}$ were used with $\mathrm{H}_{2}$ as the carrier gas. Silane and $\mathrm{CCl}_{4}$ were used for n- and p-type doping, respectively. The QDs were all grown on $\left(\begin{array}{lll}1 & 0 & 0\end{array}\right)$ GaAs substrates, while the nanowires were grown on (1 111 ) B GaAs substrates.

\section{Epitaxial Growth of In(GA)As QDs Using MOCVD}

The QD formation in the SK growth mode relies on the lattice mismatch (strain) between the material being deposited and the substrate (see for example [8] and references therein, [9]). Arguably, the best III-V QDs are grown by MBE, where its high vacuum deposition process allows a myriad of electron beam techniques to observe the in situ formation of the dots. Hence, the QD formation can be precisely controlled. In contrast, the use of in situ monitoring techniques in MOCVD is very limited and not as well developed. Furthermore, MOCVD typically uses higher temperatures $\left(50^{\circ} \mathrm{C}-100^{\circ} \mathrm{C}\right.$ greater) than MBE, in order to pyrolize the precursor gases. However, higher growth temperatures are not favorable for QD formation because of enhanced mobility of the In adatoms, which leads to the formation of larger relaxed islands.

In MOCVD, basically all of the growth parameters influence the QD formation. Section III reviews some of the important growth parameters in the formation of $\operatorname{In}_{0.5} \mathrm{Ga}_{0.5}$ As and InAs QDs on GaAs ( $\left.\begin{array}{lll}1 & 0 & 0\end{array}\right)$ substrates. InAs QDs are more susceptible to small variations in the growth conditions because of the higher strain energy associated with these dots. The lattice mismatch between $\mathrm{In}_{0.5} \mathrm{Ga}_{0.5}$ As and GaAs is $3.6 \%$, while it is $7.2 \%$ for InAs on GaAs. 

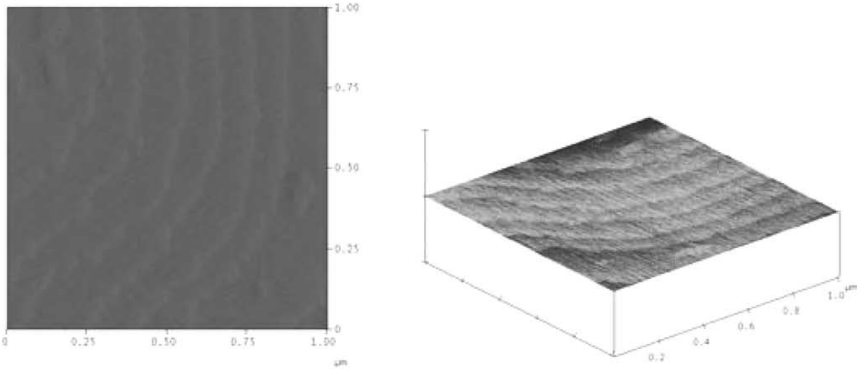

(a)
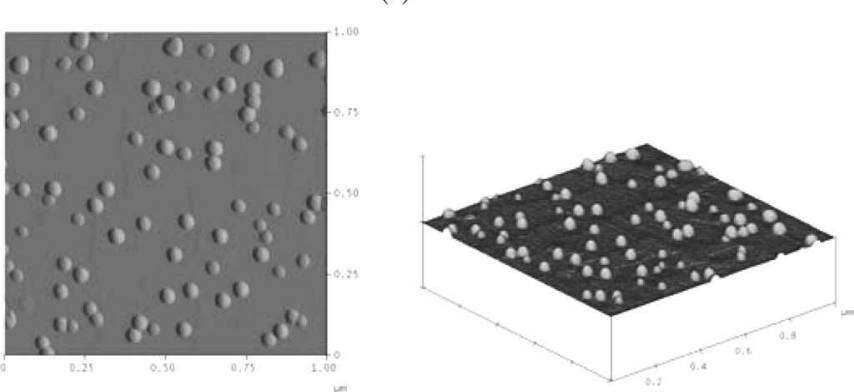

(b)
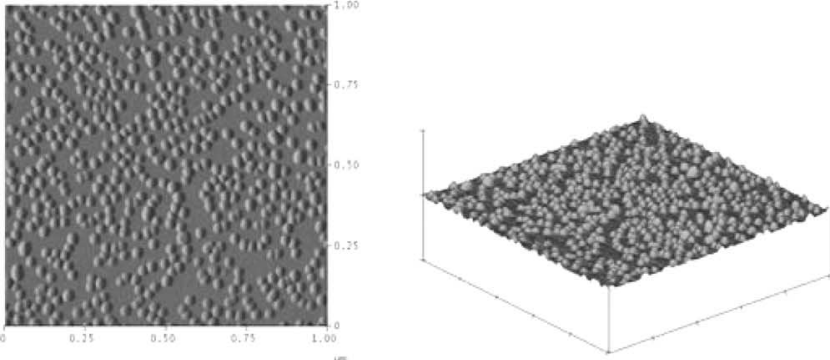

(c)
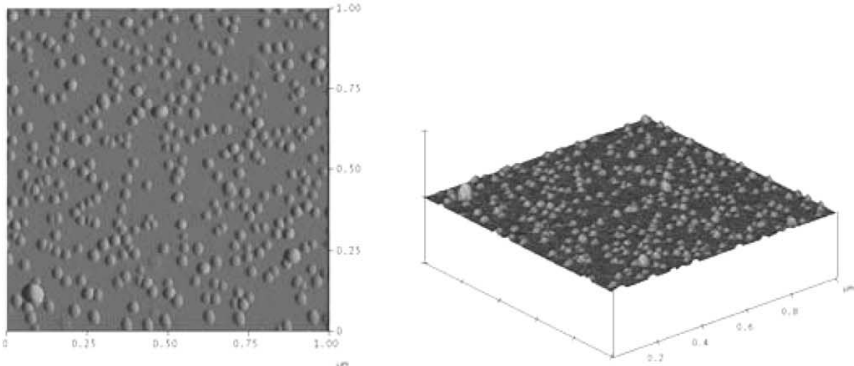

(d)

Fig. 1. AFM images of $\operatorname{In}_{0.5} \mathrm{Ga}_{0.5}$ As deposited on GaAs. The amount of material deposited was (a) 3.7 ML, (b) $4.7 \mathrm{ML}$, (c) 5.7 ML, and (d) 6 ML. The images on the left are deflection images of the surface, while the images on the right are 3-D height plots. For all images, the horizontal scale is $1 \times 1 \mu \mathrm{m}$.

\section{A. Amount of Deposited Material (Coverage)}

The nature of the SK growth mode implies that a few monolayers of two-dimensional (2-D) growth occurs prior to the QD formation. The critical thickness at which this 2-D to three-dimensional (3-D) transition occurs depends on the lattice mismatch between the layer being deposited and the substrate. For $\mathrm{In}_{0.5} \mathrm{Ga}_{0.5}$ As on GaAs, it is about 4.5 monolayers (ML) [10], [11], while for InAs on GaAs, the critical thickness is $\sim 1.7 \mathrm{ML}$ [12]-[14]. The atomic force microscopy

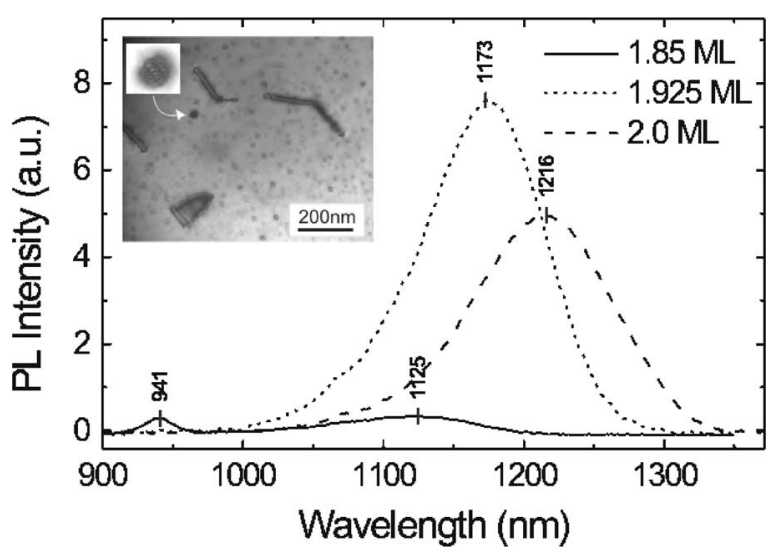

Fig. 2. RT PL spectra for InAs/GaAs QDs formed using nominal coverages of $1.85,1.925$, and $2 \mathrm{ML}$. The growth temperature was $520^{\circ} \mathrm{C}$. The inset is a plan-view TEM photograph of the 2.0-ML sample showing the formation of dislocations (adapted from [19]).

(AFM) images of Fig. 1 illustrate the QD formation process for $\mathrm{In}_{0.5} \mathrm{Ga}_{0.5}$ As deposited onto $\mathrm{GaAs}$ at $550^{\circ} \mathrm{C}$. At the lowest material coverage of $3.7 \mathrm{ML}$, the critical thickness has not been exceeded and only a 2-D wetting layer (WL) is present. In fact, the step edges of the ( 100 ) GaAs substrate can be clearly seen. Increasing the coverage to $4.7 \mathrm{ML}$ results in a very low density of dots. The dot density increases as more material is deposited until a saturation density is reached, in this case at 5.7 ML. An interesting feature observed here is that while the density increases, the size of the dots decreases. This is because of material redistribution as more dots are formed in the vicinity of existing ones. Further deposition of material (6 ML) leads to a decrease in the dot density. This is because of the formation of larger clustered islands. These larger islands tend to relax via defect formation and grow rapidly at the expense of the surrounding defect-free (coherent) QDs, thereby reducing their height and density.

In the case of InAs QDs on GaAs substrates, the larger strain results in a much more rapid 2-D to 3-D transition. This is illustrated by the photoluminescence (PL) spectra in Fig. 2 for QD samples formed at $520^{\circ} \mathrm{C}$ for different material coverage and a constant deposition rate (nominally $0.25 \mathrm{ML} / \mathrm{s}$ ). A general shift to longer wavelength is observed with increasing deposition time and indicates the formation of larger islands. At the lowest material coverage of $1.85 \mathrm{ML}$, the QD PL intensity is very low, while the WL peak is relatively strong. This is correlated with a low QD density by transmission electron microscopy (TEM) (not shown). At a coverage of $1.925 \mathrm{ML}$, the optimum QD size and density $\left(3 \times 10^{10} \mathrm{~cm}^{-2}\right)$ is obtained, with strong PL at $1173 \mathrm{~nm}$. The PL peak continues to red-shift with increasing coverage (2.0 ML), however, this is accompanied by a reduced PL intensity. This has been correlated to the formation of dislocations with a density of $\sim 1 \times 10^{8} \mathrm{~cm}^{-2}$. The inset to Fig. 2 is a plan-view TEM image that shows the larger relaxed islands and dislocations that form when too much material is deposited.

\section{B. Growth Temperature}

The QD growth is typically performed at low temperatures, for example, around $500^{\circ} \mathrm{C}$ in $\mathrm{MBE}$, in order to improve the 


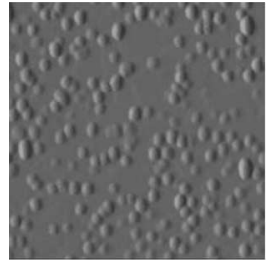

(a)

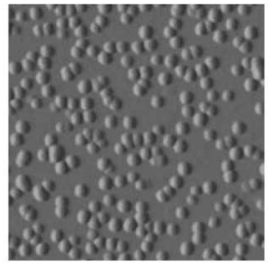

(b)

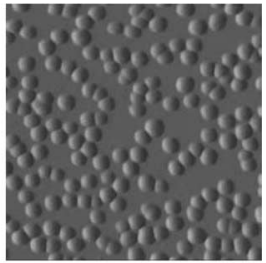

(c)

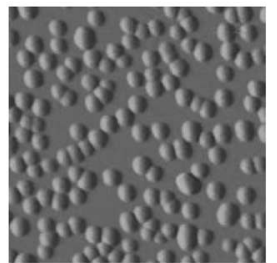

(d)

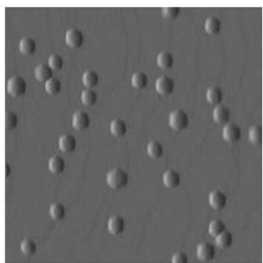

(e)
Fig. 3. AFM (deflection) images of $\mathrm{In}_{0.5} \mathrm{Ga}_{0.5} \mathrm{As}$ QDs deposited on $\mathrm{GaAs}$ at different temperatures: (a) $500{ }^{\circ} \mathrm{C}$ (b) $520^{\circ} \mathrm{C}$, (c) $540{ }^{\circ} \mathrm{C}$, (d) $550{ }^{\circ} \mathrm{C}$, and (e) $570^{\circ} \mathrm{C}$. For all images, the scale is $500 \times 500 \mathrm{~nm}$.

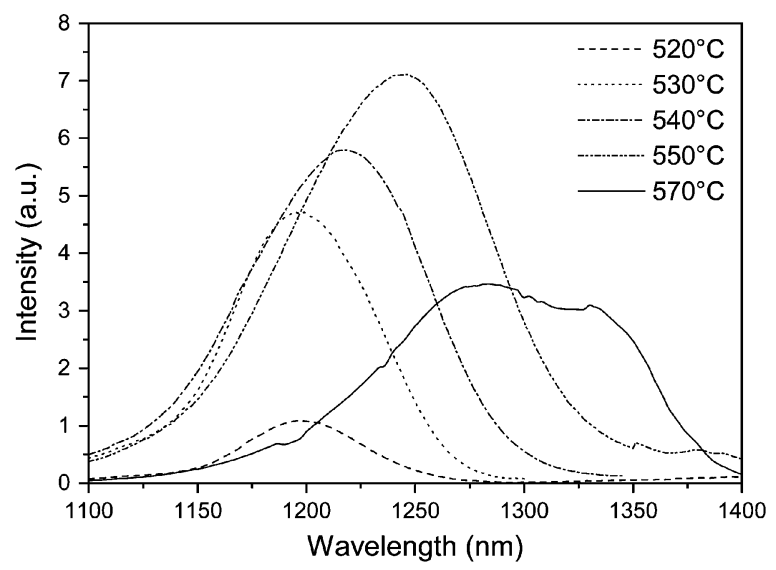

Fig. 4. RT PL spectra of buried $\operatorname{In}_{0.5} \mathrm{Ga}_{0.5} \mathrm{As}$ QDs grown at various temperatures.

QD formation. Low QD growth temperatures are desirable for two main reasons. First, they inhibit the adatom mobility across the surface reducing the tendency for large, coalesced islands to form, and second, they minimize In evaporation from the surface. However, in MOCVD growth, lower temperatures can also lead to more grown-in-defects due to insufficient decomposition of the precursor gas molecules. Using the standard precursor gases $\mathrm{AsH}_{3}, \mathrm{TMGa}$, and TMIn, this generally requires MOCVD to use higher growth temperatures than MBE, with the immediate effect that larger islands and an increased number of dislocated dots are formed [15]. In MOCVD growth, InGaAs is normally deposited at temperatures of $600^{\circ} \mathrm{C}-680^{\circ} \mathrm{C}$. In comparison, we have determined an optimum growth temperature of $\sim 550^{\circ} \mathrm{C}$ for $\operatorname{In}(\mathrm{Ga}) \mathrm{As}$ QDs and $\sim 520^{\circ} \mathrm{C}$ for InAs QDs.

The effect of the QD growth temperature is illustrated in Fig. 3 by a series of AFM images that show $\operatorname{In}_{0.5} \mathrm{Ga}_{0.5}$ As QDs grown at different temperatures between $500^{\circ} \mathrm{C}$ and $570^{\circ} \mathrm{C}$. With increasing growth temperature, the QD height increases from $\sim 1$ to $5.5 \mathrm{~nm}$, and the QD dot density decreases, consistent with an increased adatom mobility. The room temperature (RT) PL spectra for these same samples are shown in Fig. 4. Strong RT

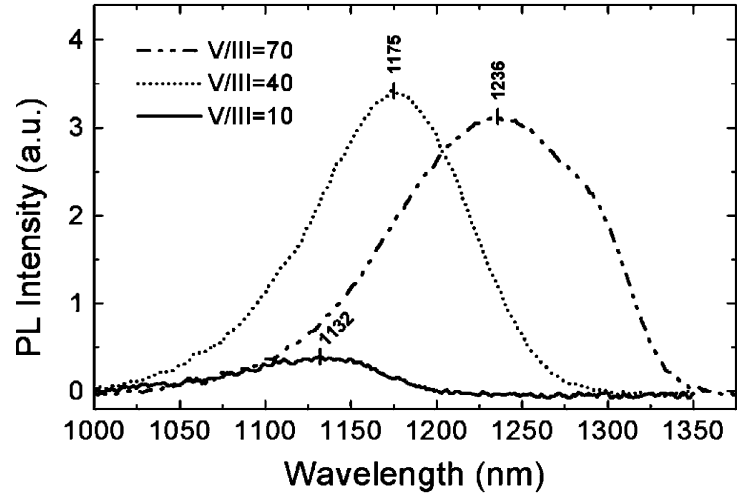

Fig. 5. RT PL spectra of InAs QD samples grown using V/III ratios of 10, 40, and $70\left(0.25 \mathrm{ML} / \mathrm{s}, 520^{\circ} \mathrm{C}, 1.95 \mathrm{ML}\right)$ (adapted from [12] and [19]).

$\mathrm{PL}$ intensity is observed at temperatures from $530^{\circ} \mathrm{C}$ to $550^{\circ} \mathrm{C}$ indicating good quality dots. The poor PL intensity at $520^{\circ} \mathrm{C}$ is likely due to poor material quality (grown-in defects), while at the highest temperature of $570{ }^{\circ} \mathrm{C}$, the clustering as observed by AFM leads to increased defect formation, again reducing the PL intensity. With increasing growth temperature, a continuous shift of the peak PL to longer wavelength is observed. This is consistent with the formation of larger islands also observed by AFM.

\section{VIIII Ratio}

The $\mathrm{V} / \mathrm{III}$ ratio is the amount of group $\mathrm{V}$ source $\left(\mathrm{AsH}_{3}\right.$ in this case) to the total group III source (TMGa + TMIn), and has a pronounced effect on the formation of QDs. In MOCVD growth, the more volatile group $\mathrm{V}$ sources are always supplied in excess (i.e., V/III ratio $\gg 1$ ), so that the growth rate is controlled by the amount of group III supplied.

RT PL spectra for InAs QDs grown on GaAs substrates are shown in Fig. 5 for three different V/III ratios. To vary the V/III ratio, only the $\mathrm{AsH}_{3}$ flow was adjusted and the other growth conditions kept fixed (growth temperature $=520^{\circ} \mathrm{C}$, growth rate $=1.95 \mathrm{MLs}$ at $0.25 \mathrm{ML} / \mathrm{s}$ ). Increasing the V/III ratio leads to a large red-shift of the PL wavelength. For example, increasing the V/III ratio from 40 to 70 shifts the PL peak by $60 \mathrm{~nm}$. This suggests that either $\mathrm{AsH}_{3}$ and/or its associated atomic hydrogen encourages the formation of larger islands [16]-[18]. In MOCVD growth using hydrides, an increased group $\mathrm{V}$ flow is also associated with an increased concentration of atomic hydrogen. A high dislocation density of $1 \times 10^{8} \mathrm{~cm}^{-2}$ was also observed in plan-view TEM images of samples grown using a V/III ratio of 70, which can be correlated to the slightly reduced PL intensity [19]. Hence, it is necessary to avoid formation of larger, ripened islands. A V/III ratio of 10 leads to extremely low intensity, blue-shifted PL, which is most likely due to a lower dot density.

It is generally accepted in epitaxial growth of lattice-matched systems that a lower V/III ratio increases the adatom mobility [20]. However, the role of the V/III ratio is still unclear for self-assembled QD growth with many conflicting reports [21]-[23]. In our case and others [22], [23], an increased QD size is observed with increasing V/III ratios, suggesting an increased adatom mobility. 


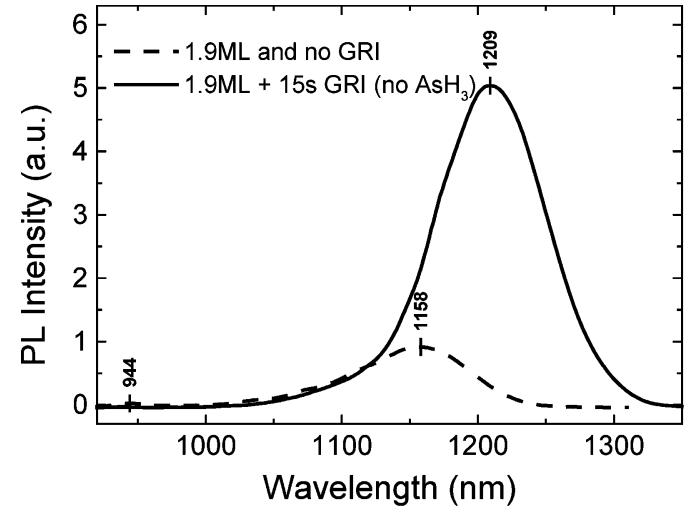

(a)

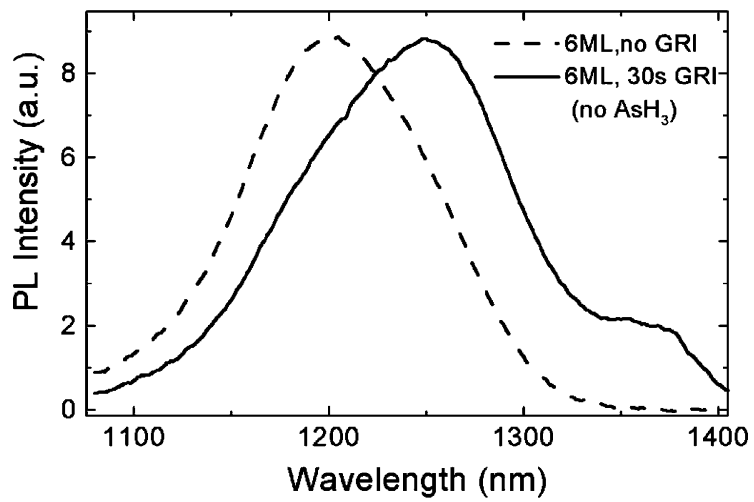

(b)

Fig. 6. RT PL spectra of (a) InAs QDs grown with and without a 15-s (no $\mathrm{AsH}_{3}$ ) growth interrupt (adapted from [19]) and (b) $\mathrm{In}_{0.5} \mathrm{Ga}_{0.5} \mathrm{As}$ QDs grown with and without a $30-\mathrm{s}\left(\right.$ no $\left.\mathrm{AsH}_{3}\right)$ growth interrupt.

\section{Growth Interrupt}

A growth interrupt (GRI) involves temporarily stopping the growth for a short period of time by removing all precursors. Due to the high mobility of In adatoms and the high strain involved, material continues to redistribute between the QDs and the WL (to reach an equilibrium state) after the sources are switched off [24]-[27]. GRIs have also been reported to reduce the defect density [12]. Typically, the deposition is stopped and a GRI introduced just prior to QD formation (i.e., just before the 2-D to 3-D transition) or just after the formation of QDs (i.e., very low density). In this way, an optimum QD ensemble can be formed. However, if a GRI is introduced after too much material has been deposited, large dislocated islands may form.

This is illustrated by the RT PL spectra in Fig. 6(a) and (b). In Fig. 6(a), InAs is deposited so that the 2-D to 3-D transition is just exceeded (i.e., so that a low density of "undeveloped" dots is formed). The dots are either capped immediately or followed by a 15 -s GRI (no $\mathrm{AsH}_{3}$ ) prior to capping. With no GRI, only a low density of dots formed with low intensity PL at $1158 \mathrm{~nm}$. The GRI clearly allows further material redistribution and development of the QDs, with strong red-shifted PL at $1209 \mathrm{~nm}$. The WL intensity at $944 \mathrm{~nm}$ is also reduced and blueshifted confirming that material is redistributed from the WL to the QDs during the interrupt period. Both spectra in Fig. 6(a) have a similar linewidth of $\sim 95 \mathrm{~nm}$. However, dots formed using a GRI tend to have smaller PL linewidths compared to fully developed dots formed with no GRI (not shown).

In Fig. 6(b), 6 MLs of $\operatorname{In}_{0.5} \mathrm{Ga}_{0.5}$ As is deposited resulting in well-developed dots. The dots are either capped immediately or followed by a 30-s GRI (no $\mathrm{AsH}_{3}$ ) prior to capping. The GRI again causes a red-shift of the PL peak. However, this time the situation is more complicated with the formation of a pronounced shoulder on the long wavelength side. In the case of InGaAs QDs, the red-shift or this shoulder may be due to a combination of increased dot size and/or indium enrichment as a result of preferential In migration from the strained WL to the QDs.

It is also worth mentioning that the presence of $\mathrm{AsH}_{3}$ during a GRI, especially in the case of InAs/GaAs QDs leads to strong island ripening and a dramatic decrease in PL intensity (not shown). It has been suggested that higher $\mathrm{AsH}_{3}$ flows (and/or its associated atomic hydrogen) destabilizes the WL leading to the formation of large defective islands [12].

\section{SAE}

SAE is a promising technique to deposit material of different thicknesses and compositions on different parts of the same wafer through patterning [28]-[30]. This eliminates the butt-joint problem of the traditional etch-regrowth technique for fabricating integrated photonic devices. Typically, in SAE, the substrate is patterned with a dielectric layer ( such as $\mathrm{SiO}_{2}$ ). Growth does not take place over the dielectric layer. Hence, the growth species migrate toward the mask openings. By changing the widths of the masks and the openings between the masks, the growth rate in the opening region may be enhanced in a controllable fashion. In addition, a composition gradient may also develop in the openings due to the different adatom mobilities. Hence the in-plane bandgap can be controlled for the integration of optoelectronic devices.

The mask used in this paper consists of pairs of $\mathrm{SiO}_{2}$ stripes of varying dimensions. For the results discussed here, the opening or spacing between the two $\mathrm{SiO}_{2}$ stripes is fixed at $50 \mu \mathrm{m}$, while the stripe width is varied to adjust the growth enhancement. The $\mathrm{SiO}_{2}$ is deposited at $300{ }^{\circ} \mathrm{C}$ by plasma-enhanced CVD and patterned by standard photolithography and subsequently etched in a buffered HF solution. Further details may be found in [31]. Fig. 7 shows AFM images of uncapped $\mathrm{In}_{0.5} \mathrm{Ga}_{0.5} \mathrm{As}$ QDs formed in the 50- $\mu$ m openings with various stripe widths. The amount of InGaAs deposited is $3.4 \mathrm{ML}$ (in an unpatterned region), which is less than the 4.5-ML critical thickness required for the 2-D to 3-D transition to take place for $\mathrm{In}_{0.5} \mathrm{Ga}_{0.5} \mathrm{As}$ on GaAs. Therefore, in regions far away from the mask [Fig. 7(a)], where there is no growth enhancement, only a thin QW (WL) is formed. For the smallest oxide stripe width of $5 \mu \mathrm{m}$, there is only minimal diffusion of the growth species into the openings, which is not sufficient to increase the thickness of material deposited beyond the critical thickness of 4.5 ML. However, as the mask width is increased to $12 \mu \mathrm{m}$, there is enough diffusion of growth species into the opening to effectively increase the thickness of deposited material to exceed the critical thickness for the 2-D to 3-D transition to take place. Hence, a low density of QDs is observed [Fig. 7(c)]. As the mask width is 


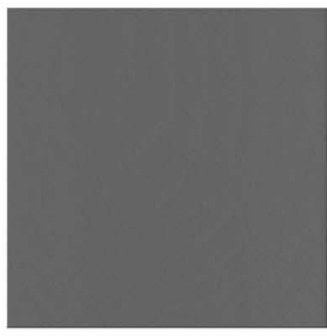

(a)

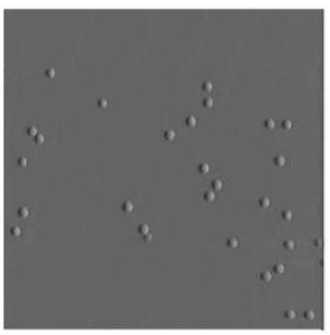

(c)

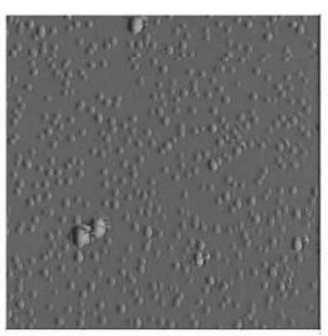

(e)

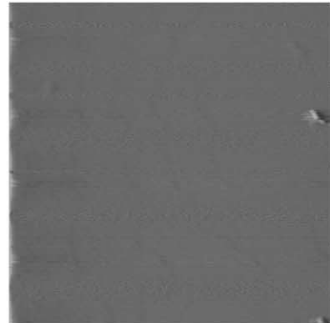

(b)

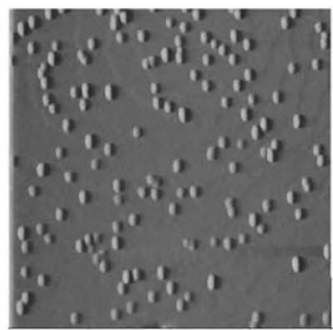

(d)

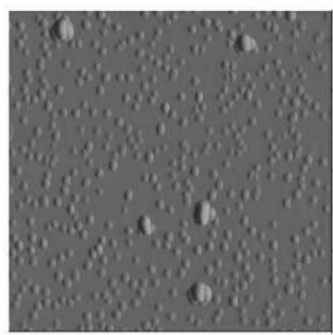

(f)

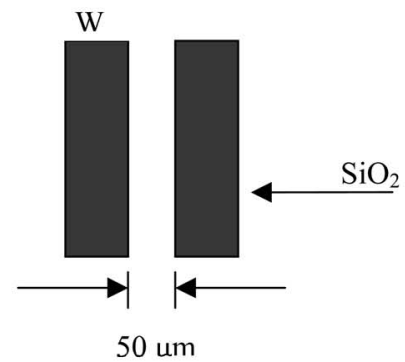

(g)

Fig. 7. AFM (deflection) images of $\mathrm{In}_{0.5} \mathrm{Ga}_{0.5} \mathrm{As}$ QDs formed in a $50-\mu \mathrm{m}$ opening between two $\mathrm{SiO}_{2}$ stripes of widths (W) (b) $5 \mu \mathrm{m}$, (c) $12 \mu \mathrm{m}$, (d) $25 \mu \mathrm{m}$, (e) $35 \mu \mathrm{m}$, and (f) $50 \mu \mathrm{m}$. Also shown are images of the growth surface of an unpatterned substrate (a) and a schematic of the mask geometry used in this work $(\mathrm{g})$.

further increased, the density of the QDs starts to increase until a saturation level is reached at around a stripe width of $35 \mu \mathrm{m}$ [Fig. 7(e)] at which large dislocated islands begin to appear. As more material diffuses into the opening with further increase in the mask width [Fig. 7(f)], it is preferentially drawn into these energetically favored large incoherent clusters to further increase their size and density. Similar effects are observed if the openings are reduced to smaller dimensions. In this case, the saturation of QD density (and formation of larger dislocated islands) occurs at a correspondingly smaller mask width.

Fig. 8(a) shows the cathodoluminescence (CL) spectra from the buried InGaAs QDs similar to the samples considered earlier with three different oxide stripe widths. The spectra were

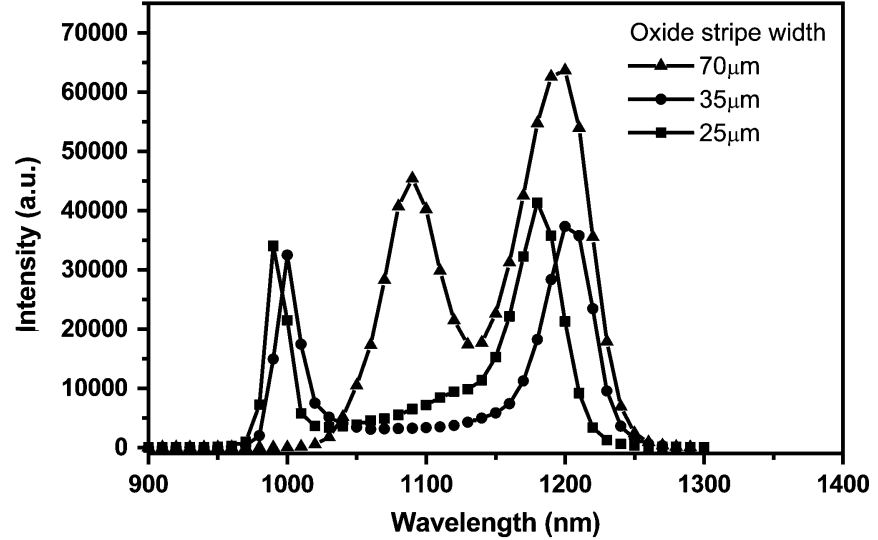

(a)

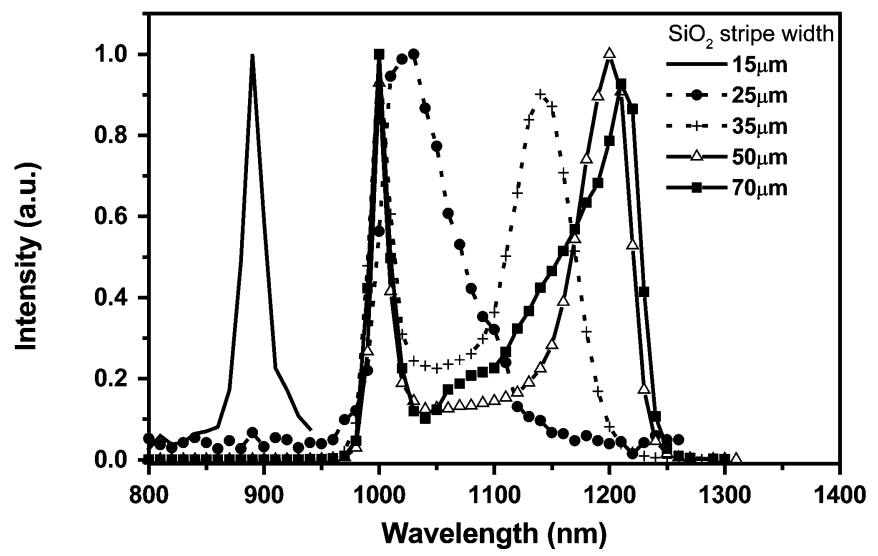

(b)

Fig. 8. 77-K CL spectra for (a) $\mathrm{In}_{0.5} \mathrm{Ga}_{0.5} \mathrm{As}$ and (b) InAs QDs deposited in a $50-\mu \mathrm{m}$ opening region between two $\mathrm{SiO}_{2}$ stripes of different widths.

collected at $77 \mathrm{~K}$ from the middle region of the $50-\mu \mathrm{m}$ openings. Two peaks were observed in all the samples, corresponding to the WL and the QD emission. The QD peak gradually red-shifts (as the dots get larger) with increasing oxide stripe width but saturates when the width is $70 \mu \mathrm{m}$. The shift in the WL peak, however, is more prominent and this is attributed to a change in the composition on the WL with increasing stripe width. Since the mobility of In and Ga adatoms are very different, in regions where the oxide width is larger, it is expected that more In adatoms will diffuse into the openings than $\mathrm{Ga}$. Hence, the In mole fraction of the WL is increased, thereby red-shifting the emission peak. This is further confirmed by the results for InAs QDs (described later), where the WL peak remains essentially constant since only In adatoms are involved in this case.

Fig. 8(b) shows the 77-K CL spectra for samples of InAs QDs grown on prepatterned GaAs substrates. The thickness of InAs deposited is 1.2 ML (on unpatterned substrates), which is smaller than the critical thickness of $1.7 \mathrm{ML}$ for the 2-D to 3-D transition to take place in the InAs/GaAs system. In regions where the stripe width is $15 \mu \mathrm{m}$, QD formation is not observed as indicated by a narrow signal at $880 \mathrm{~nm}$ (WL peak) due to insufficient material diffusion from the $\mathrm{SiO}_{2}$ to form QDs. For a stripe width of $25 \mu \mathrm{m}$, this WL becomes thicker and the emission peak red-shifts. Also, this WL peak overlaps with a broader peak. The broader peak on the long wavelength side is attributed 
to QDs that are just beginning to form. Further increase in the $\mathrm{SiO}_{2}$ stripe width results in more material diffusion into the opening and the QDs become larger and denser as indicated by the red-shift of the broad QD peak. However, the sharp WL peak remains at the same position. Finally, when the stripe width is too large $(70 \mu \mathrm{m})$, the QD peak does not seem to red-shift further suggesting a critical size and density have been achieved and any further material will only result in the formation of large dislocated islands.

\section{QD LASERS}

Over the past decade, many of the advantages predicted for QD lasers [32], [33] have been demonstrated. For example, low threshold currents of the order of $20 \mathrm{~A} / \mathrm{cm}^{2}$ per dot layer [34]-[36] and high thermal stability with characteristic temperatures as high as $300 \mathrm{~K}$ at room temperature [36]-[38] have been reported. However, it is still difficult to achieve all of the characteristics discussed earlier in one device, with only a few such reports [36], [37]. Most reports show a high susceptibility of the QD lasers to excited state lasing, which is associated with both higher threshold currents and reduced efficiencies [39]-[42]. This excited state lasing is due to the limited ground state gain provided by the QDs and the higher gain provided by the excited states and even the WLs [43]. To overcome this limitation, low-loss cavity designs (e.g., long cavities and high-reflection coatings) are often used. However, this leads to poor differential efficiencies unsuitable for higher power operation [34], [35]. A better alternative is to increase the overall QD density and hence ground state gain by stacking multiple dot layers [40], [44].

In Section V, we compare the properties of thin p-clad lasers incorporating either three or five stacked layers of $\operatorname{In}_{0.5} \mathrm{Ga}_{0.5} \mathrm{As}$ QDs. The dot layers are separated by 30-nm GaAs spacers and smoothing procedures used to planarize the growth front of each spacer layer prior to deposition of the QDs. This results in a strong RT PL from the stacked QD layers with similar emission wavelength and linewidth as that of a single layer. InAs QD lasers are briefly compared to the $\mathrm{In}_{0.5} \mathrm{Ga}_{0.5} \mathrm{As}$ QD lasers at the end of Section $\mathrm{V}$, but show the same general behavior.

The thin p-clad laser structures are grown and processed into $4-\mu \mathrm{m}$ ridge waveguide structures. Thin $\mathrm{p}$-clad laser structure has several advantages. It allows lower Al content cladding layers to be used and also reduces the growth time for the layers above the QDs. This is important because the QDs are very sensitive to the growth temperatures used for the overlayers with their emission blue-shifting strongly at temperatures above $650{ }^{\circ} \mathrm{C}$. The top p-cladding AlGaAs layers are also grown at $650^{\circ} \mathrm{C}$, much lower than the optimal $750^{\circ} \mathrm{C}$ growth temperature used for the lower n-cladding layers, in order to minimize this effect. Further details on the thin p-cladding laser structure can be found in [45] and [46].

\section{A. InGaAs QD Lasers}

The lasing spectra for a three-stacked QD laser structure with different cavity lengths are shown in Fig. 9. The devices are tested at RT under pulsed conditions $(25 \mathrm{kHz}, 2 \mu \mathrm{s})$ and the lasing spectra recorded at $1.1 I_{\mathrm{th}}$. With decreasing device length

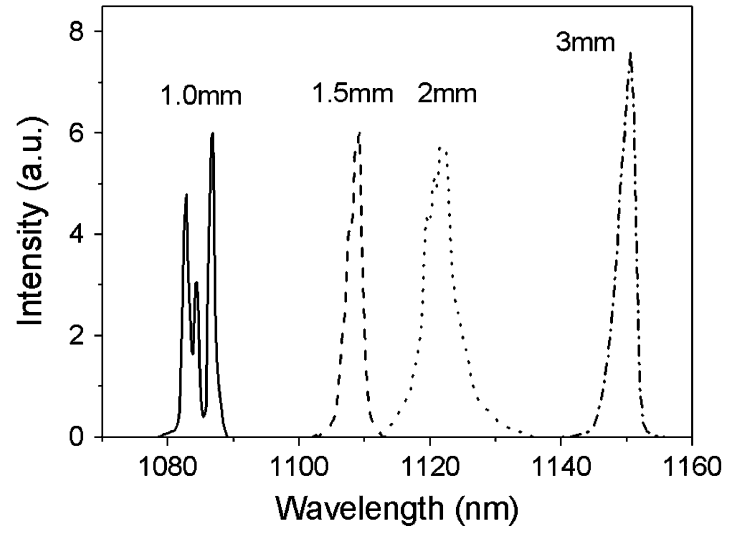

Fig. 9. Lasing spectra for a three-stacked $\operatorname{In}_{0.5} \mathrm{Ga}_{0.5}$ As QD laser at various cavity lengths. Measurements were taken at room temperature under pulsed conditions $\left(25 \mathrm{kHz}, 2-\mu\right.$ s pulse width) and the spectra taken at $1.1 I_{\text {th }}$ (adapted from [46]).

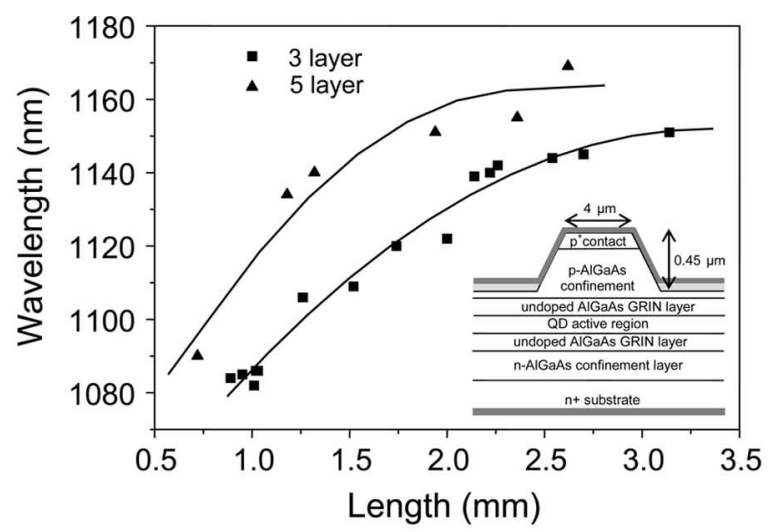

(a)

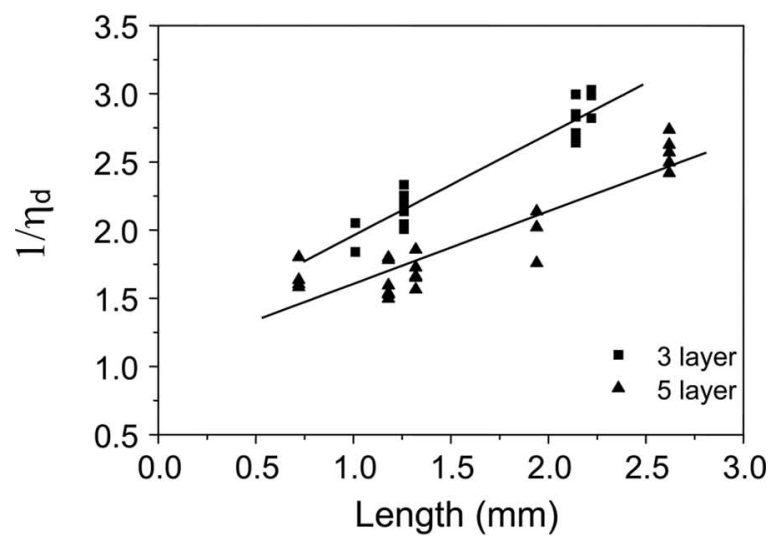

(b)

Fig. 10. (a) Lasing wavelength and (b) inverse differential efficiency versus cavity length for three- and five-stacked $\operatorname{In}_{0.5} \mathrm{Ga}_{0.5}$ As QD lasers.

and hence increasing cavity losses, the emission wavelength shows a continuous shift to shorter wavelength due to state filling effects. This indicates that the shorter devices are lasing from excited states due to insufficient ground state gain. At the longest cavity length of $3 \mathrm{~mm}$, the lasing wavelength is approaching that of the PL peak, indicating that the cavity losses are now low enough for near ground state lasing.

Fig. 10(a) compares the shift in lasing wavelength with cavity length for a three- and five-stacked QD laser. Clearly, the 


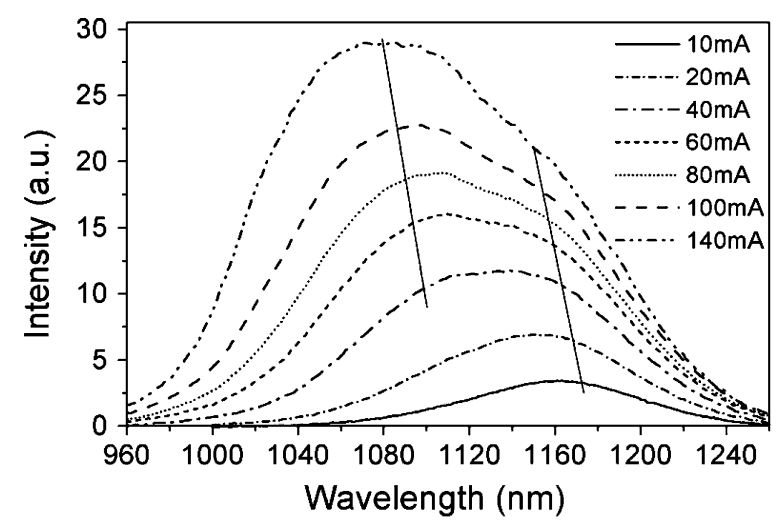

(a)

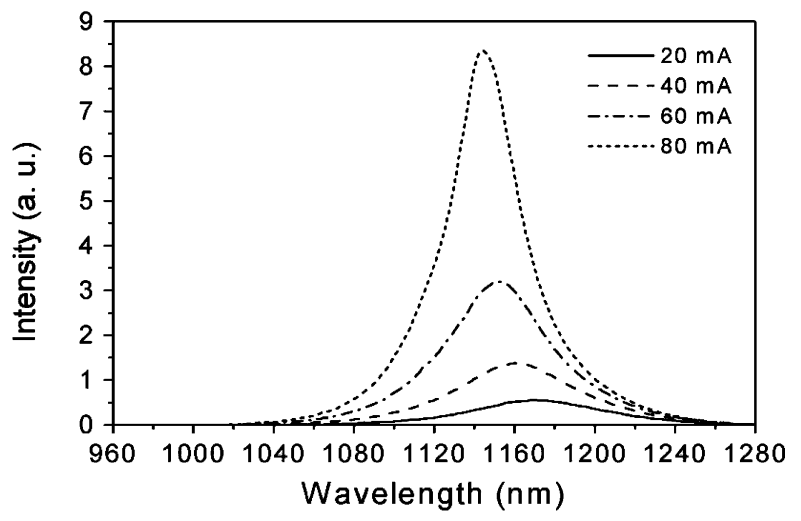

(b)

Fig. 11. Edge facet electroluminescence from $\operatorname{In}_{0.5} \mathrm{Ga}_{0.5} \mathrm{As}$ QD laser. (a) Three-stacked (adapted from [47]). (b) Five-stacked.

increased gain volume enables the five-stacked device to consistently lase at longer wavelength than the three-stacked device for any given cavity length. Also the five-stacked devices continue to lase from the ground state at much shorter cavity lengths.

Additional insight into the laser operation and state filling effects can be gained by monitoring the electroluminescence with increasing injection current up to threshold. Fig. 11(a) and (b) shows electroluminescence spectra for a three- and five-stacked QD laser of similar length $(\sim 1 \mathrm{~mm})$, respectively. In the case of the three-stacked laser, a gradual saturation of the ground state is visible followed by the onset of at least one excited state, with lasing eventually occurring from this excited state. In the case of the five-stacked laser structure, the ground state gain is sufficiently high so that no excited state spontaneous emission is observed and lasing occurs from the ground state. A clear blue-shift of the electroluminescence peak, for both the ground and excited dot states is observed as the injection current is increased. Our modeling studies have shown that this blue-shift is primarily a consequence of the large QD size distribution and Fermi-Dirac-like carrier population of the dots [47]. With increasing carrier injection, smaller QDs with higher lying energy states are increasingly populated. A built-in electric dipole may also contribute slightly to the blue-shift [3], [48]. QDs are frequently reported to have a nonuniform In composition and either a lens or truncated pyramid shape. Modeling has shown this to result in a built-in electric field across the QD, in a direction

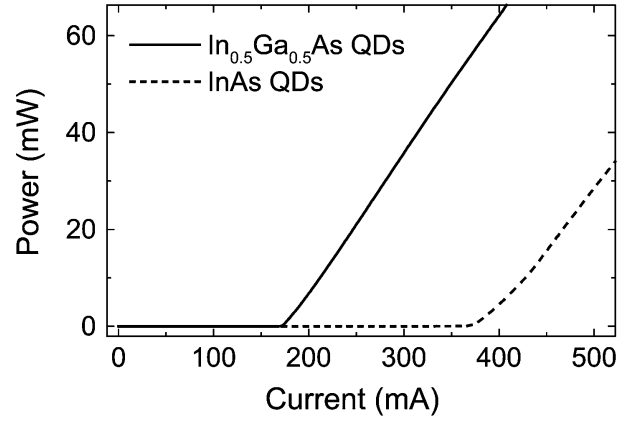

Fig. 12. Light output versus injected current curve for an $\operatorname{In}_{0.5} \mathrm{Ga}_{0.5} \mathrm{As}$ and an InAs QD laser. Both devices are 2.7-mm long with three-stacked layers of QDs. The lasers were tested at room temperature under pulsed conditions $(25 \mathrm{kHz}$, $2-\mu$ s pulse width).

opposite to the growth direction [49], [50]. This built-in electric dipole causes a reduction in the ground state gain as carriers have to compensate the field before maximum gain is achieved.

Fig. 10(b) compares plots of inverse differential efficiency versus cavity length for the same three- and five-stacked QD lasers. From a least square fit of the data in Fig. 10(b), the internal quantum efficiency was calculated to be $83 \%$ and $93 \%$ for the three- and five-stacked QD lasers, respectively. The higher efficiency for the five-stacked structure is likely due to a reduced population of the excited states, which, in turn, reduces carrier escape from the QDs to the WL. The internal losses were also determined to be $7.4 \pm 1.2 \mathrm{~cm}^{-1}$ and $5.9 \pm 1.7 \mathrm{~cm}^{-1}$ for the three- and five-stacked lasers, respectively, indicating that an increased number of QD layers does not increase the scattering losses. For a fixed cavity length, the threshold current for the five-stacked device is consistently smaller than that for the three-stacked device (not shown) consistent with an increased ground state gain.

\section{B. InAs $Q D$ Lasers}

Lasers have also been fabricated from stacked layers of InAs QDs and are briefly compared in this paper with the $\mathrm{In}_{0.5} \mathrm{Ga}_{0.5}$ As QD lasers. The higher lattice mismatch and strain in the InAs/GaAs QD system imposes more severe restrictions on both the QD growth conditions and the growth conditions used for the overlayers. As a result, the top AlGaAs cladding layers of the InAs QD laser structure have to be grown at $600^{\circ} \mathrm{C}$, $50{ }^{\circ} \mathrm{C}$ lower than that used for the $\mathrm{In}_{0.5} \mathrm{Ga}_{0.5} \mathrm{As}$ QD lasers. This results in poorer quality AlGaAs cladding layers and a doubling of the threshold current as shown by the $L-I$ curves in Fig. 12 . This is attributed to a reduced injection efficiency of carriers into the active region due to increased carrier recombination in the cladding layer [51].

\section{QD INFRARED PHOTODETECTORS}

Another important application of self-organized QDs is the infrared photodetectors that are used for midwavelength $(3-5 \mu \mathrm{m})$ and long-wavelength $(8-14 \mu \mathrm{m})$ photon detection [52]-[57]. Compared with their more developed QW counterpart, QD infrared photodetectors (QDIPs) offer 

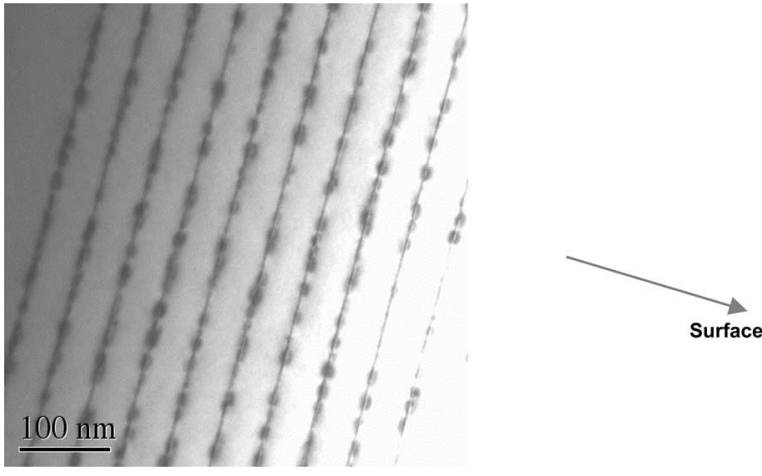

Fig. 13. Cross-sectional TEM image of the 15-layer QDIP structure.

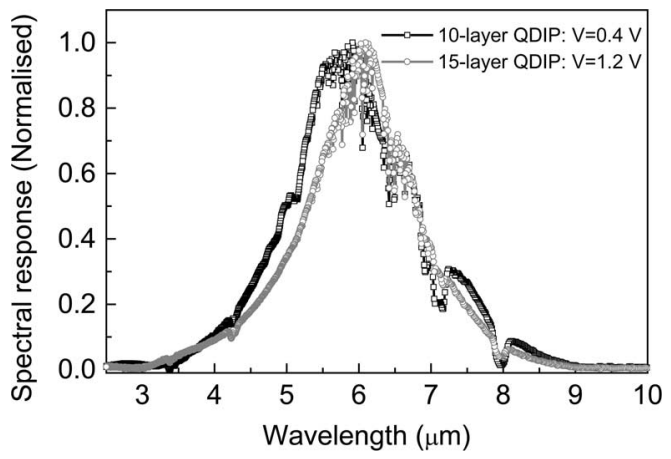

Fig. 14. 77-K spectral response from the 10- and 15-layer QDIPs.

improved device performances such as sensitivity to normal incidence infrared radiation, lower dark current, and higher responsivity and detectivity owing to the discrete nature of carrier confinement in QDs [58], [59]. However, in order to increase the light absorption in QDIPs, multiple QD layers $(>5)$ are normally required. Issues like strain accumulation and easy formation of dislocations could be detrimental to device application, making the dot growth even more challenging especially for MOCVD where higher growth temperatures are used, as discussed in earlier sections. To the best of our knowledge, among the few reports on MOCVD-grown QDIPs [60]-[64], there is only one group that has demonstrated fully characterized InGaAs/InGaP QDIPs with excellent performance [62]-[64].

The results from two n-i-n QDIP structures [65], [66] with 10- and 15-layers of $\operatorname{In}_{0.5} \mathrm{Ga}_{0.5}$ As QDs are presented in Section VI. The QD layers were formed by depositing 5.7 MLs of undoped InGaAs and were separated by $50-\mathrm{nm}$ GaAs barrier layers. The stacked dot layers were sandwiched between two highly Si-doped top $(300 \mathrm{~nm})$ and bottom $(1000 \mathrm{~nm}) \mathrm{GaAs}$ contact layers. The other growth details can be found in [65]. Fig. 13 shows a cross-sectional TEM photograph of the 15-layer QDIP structure where no obvious formation of lattice defects such as dislocations can be observed, confirming the excellent material quality. Fig. 14 shows the 77-K normal incidence spectral response from the two devices measured with a fourier transform infrared spectrometer and a low-noise current preamplifier. The two devices exhibit similar peak wavelengths and spectral linewidths. The 10-layer sample peaks at $5.9 \mu \mathrm{m}(210 \mathrm{meV})$

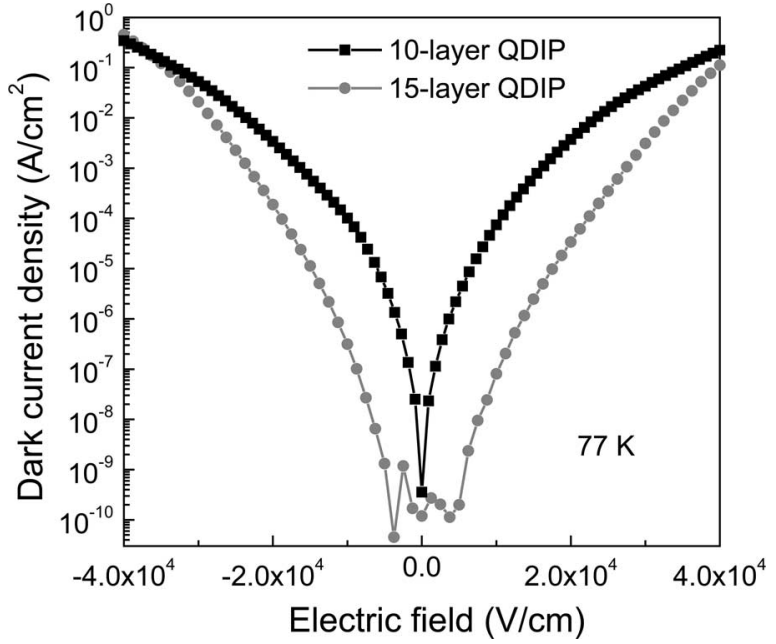

Fig. 15. 77-K dark current characteristics for the 10- and 15-layer QDIPs.

with $31 \%$ linewidth $(\Delta \lambda / \lambda)$, while the 15-layer device peaks at $6 \mu \mathrm{m}(207 \mathrm{meV})$ with $25 \%$ linewidth, suggesting that the growth of the additional five layer of dots has little influence on the formation of QDs and their properties. The large energy spacing and broad linewidth suggest that both QDIPs have a bound-to-continuum transition and this has been confirmed by theoretical simulations [66]. In addition, the broadening of the spectrum is also a result of the nonuniform size distribution of the self-organized QDs.

The dark current characteristics of the samples are shown in Fig. 15. To make a direct comparison between the two samples, the dark current density is plotted as a function of the applied electric field (instead of bias voltage). Within the applied electric field $\left(-4 \times 10^{4} \mathrm{~V} / \mathrm{cm}<E<4 \times 10^{4} \mathrm{~V} / \mathrm{cm}\right)$, the 15-layer device shows a much lower dark current density than that of the 10-layer device. In our QDIP structures, the QDs are undoped and the carriers are supplied through background doping and electron injection from the contact layers. At small electric fields, as the electric field is increased, more electrons populate the QDs, resulting in an increase in the average sheet electron density and hence an increased dark current [51]. When a large fraction of the QD states are filled, further increase of the electric field does not significantly change the sheet electron density. However, it will lower the energy barrier for injected electrons, thereby causing some increase in dark current. For the 15-layer QDIP, the average sheet electron density of the QDs is lower than that of the 10-layer QDIP under the same electric field, because of the larger number of QD layers. Therefore, a lower dark current density is observed in the 15-layer sample. As more and more dot states are filled because of the injection of electrons from the contact layer, the dark current increases rapidly to the same level as that of the 10-layer device.

Similarly, because of the lower average sheet electron density under the same electric field, lower responsivity is obtained in the 15-layer QDIP than in the 10-layer QDIP, as shown in Fig. 16(a). The overall performance of the detectors, which is represented by specific detectivity, is plotted in Fig. 16(b). A maximum peak detectivity of $1.6 \times 10^{9} \mathrm{~cm} \cdot \mathrm{Hz}^{1 / 2} / \mathrm{W}$ with the 


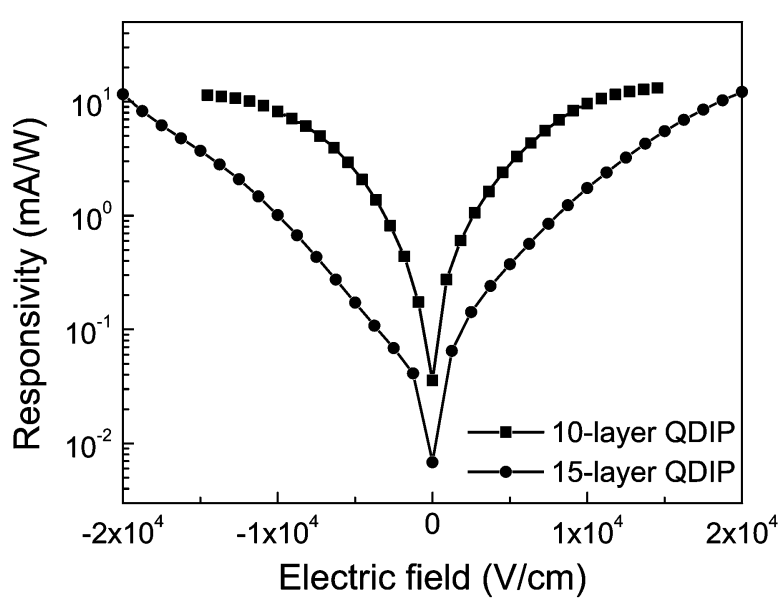

(a)

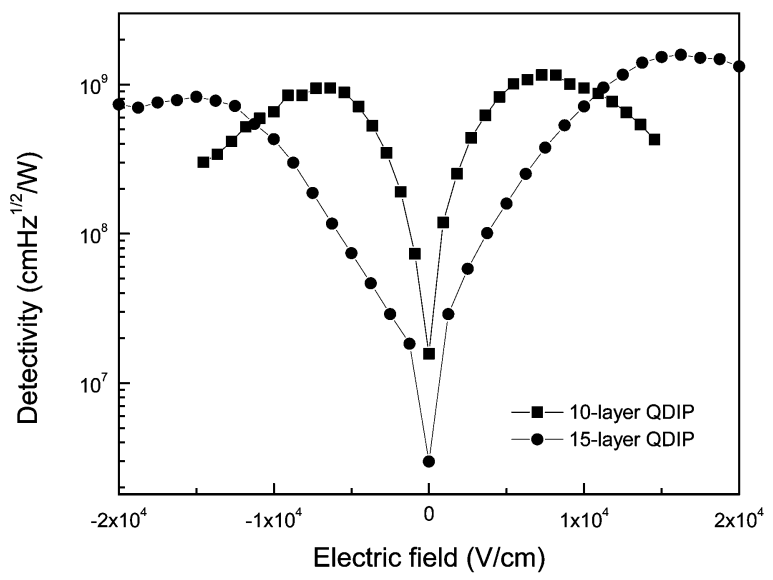

(b)

Fig. 16. (a) Peak responsivity and (b) detectivity for the 10- and 15-layer QDIPs.

corresponding peak responsivity of $6.9 \mathrm{~mA} / \mathrm{W}$ are obtained from the 15-layer device, showing a slightly better performance than the 10-layer one, which has the maximum peak detectivity of $1.2 \times 10^{9} \mathrm{~cm} . \mathrm{Hz}^{1 / 2} / \mathrm{W}$ and a corresponding peak responsivity of $5.6 \mathrm{~mA} / \mathrm{W}$. This is comparable to the reported value $(1.5 \times$ $10^{9} \mathrm{~cm} \cdot \mathrm{Hz}^{1 / 2} / \mathrm{W}$ ) of a similar Al-free InAs/GaAs QDIP grown by MBE [67], demonstrating the good quality of our MOCVD QDIPs.

On the basis of these results, increasing the number of dot layers does not seem to lead to significant improvements in device performance. This is in contrast to several other reports [68], [69] that demonstrate excellent performance for devices with 30 and 70 dot layers, respectively. In our QDIPs, the active region is undoped, whereas in [68] and [69], the dots are directly doped. This indicates that the supply of carriers may not be sufficient for our 15-layer QDIPs, which is also consistent with the much lower responsivity of this device. Hence, superior performance for the 15-layer QDIPs may be possible with further optimization of the doping scheme. Finally, the photoconductive gain may also vary with the number of QD layers, possibly limiting the ultimate improvement in QDIP performance with increasing dot layers.

\section{NANOWIRES}

The anisotropic growth of silicon whiskers via the VLS growth mechanism was discovered by Wagner and Ellis four decades ago [70]. According to this mechanism, a small (micrometer-sized) Au particle on the semiconductor surface (Si) forms a eutectic liquid alloy with the host material at growth temperature. The liquid droplet is an ideal sink for reaction species supplied from the surrounding vapor and is readily supersaturated with reaction species. The precipitation of reaction species predominantly occurs at the liquid/solid interface and leads to highly anisotropic growth.

The kinetics of VLS growth mode was extensively investigated in the 1970s. Specifically, the correlation between silicon whisker height and the diameter of the Au liquid droplet was explained in terms of the Gibbs-Thomson effect [71]. Recently, some scientists have noticed the importance of these quasione-dimensional (1-D) structures if micrometer-sized whiskers are scaled down to nanowires [72]. In addition, axial and radial heterostructure nanowires have been proposed as promising nanobuilding blocks for future optoelectronic devices [73]. Nanowire lasers [73], [74], resonant tunneling diodes [74], and single-electron tunneling diodes [75] have been demonstrated. Though the achievements in III-V nanowires are remarkable, their growth mechanism is still in controversy. One of the research groups has proposed the vapor-solid-solid growth mechanism rather than the VLS mechanism [75]. Nanowires have been fabricated via laser ablation [72], MBE [76], chemical beam epitaxy [74], and MOCVD [77], [78]. MOCVD may be a potentially important growth technique for nanowires fabrication due to its versatility.

Our experiments start with undoped GaAs $\left(\begin{array}{lll}1 & 1 & 1\end{array}\right)$ B substrates that are functionalized by dipping in $0.1 \%$ poly-L-lysine (PLL) solution. Commercially available Au colloid liquid is dispersed on the substrate surface. The PLL acts as a positively charged polyelectrolyte that attracts the negatively charged $\mathrm{Au}$ nanoparticles and immobilizes them on the substrate surface. Prior to nanowire formation, the substrate is annealed in situ at $600{ }^{\circ} \mathrm{C}$ under $\mathrm{AsH}_{3}$ ambient to desorb surface contaminants and to promote the eutectic $\mathrm{Au} / \mathrm{Ga}$ alloy formation.

Fig. 17 shows field emission scanning electron microscope (FESEM) images of GaAs nanowires grown at various temperatures $\left(390^{\circ} \mathrm{C}-510^{\circ} \mathrm{C}\right)$, taken with the substrates tilted $45^{\circ}$ from the electron beam. A 30-nm Au colloidal solution was used. The nanowire height increases with increasing growth temperature up to $480^{\circ} \mathrm{C}$ and then decreases at higher temperatures, while tapering of the nanowires increases continuously. Tapering is due to the effect of radial growth. If the growth of nanowires is dominated by the reaction species impinging directly on the $\mathrm{Au}$ nanoparticles on the top of the nanowires, ideal 1-D nanowire growth is achieved without any tapering. However, a significant amount of reaction species could also have arrived at the nanowire sidewall or ( $\left.\begin{array}{lll}1 & 1 & 1\end{array}\right)$ B substrate and diffused toward the Au nanoparticle. During the migration process, the incorporation of the reaction species into the (1 111 1) B surface and nanowire sidewall takes place at high growth temperature. This incorporation, known as the 2-D growth, results in the tapering. 


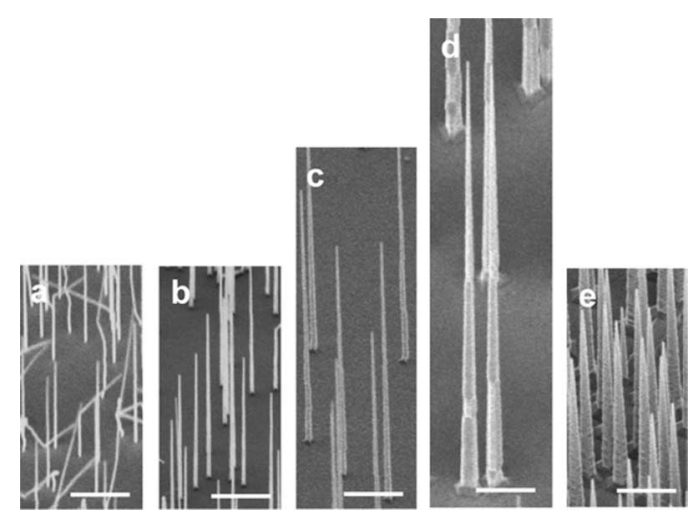

Fig. 17. $45^{\circ}$ tilt FESEM images of GaAs nanowires with various growth temperatures of (a) $390^{\circ} \mathrm{C}$, (b) $410^{\circ} \mathrm{C}$, (c) $450^{\circ} \mathrm{C}$, (d) $480^{\circ} \mathrm{C}$, and (e) $510^{\circ} \mathrm{C}$. Scale bars are $1 \mu \mathrm{m}$.
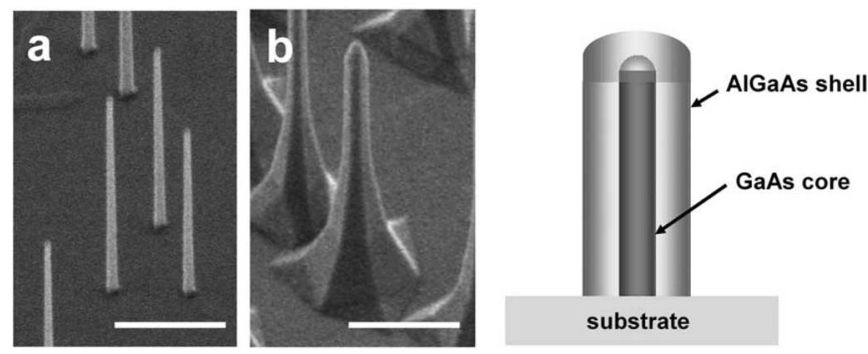

Fig. 18. $\quad 45^{\circ}$ tilted FESEM image of (a) core GaAs nanowires and (b) core/shell GaAs/AlGaAs heterostructure nanowires. Scale bars are $1 \mu \mathrm{m}$. A schematic illustrates the GaAs/AlGaAs core/shell structure.

The decrease of apparent nanowire height at $510^{\circ} \mathrm{C}$ is due to the increase of 2-D growth at ( $\left.\begin{array}{lll}1 & 1 & 1\end{array}\right)$ B substrate. From Fig. 17, the optimized growth temperature is in the range of $420^{\circ} \mathrm{C}-450{ }^{\circ} \mathrm{C}$ with very little tapering and reasonable uniformity.

Another interesting class of nanowires is the core-shell heterostructure nanowires. Fig. 18(a) shows GaAs nanowires grown by using $50-\mathrm{nm}$ gold colloidal solution. After the growth of the core GaAs nanowires at $450{ }^{\circ} \mathrm{C}$, the growth temperature is increased to $650^{\circ} \mathrm{C}$ followed by the deposition of $\mathrm{Al}_{0.27} \mathrm{Ga}_{0.73}$ As. Sidewall (2-D) growth dominates over the 1-D growth at $\mathrm{Au} /$ nanowire interface at this high growth temperature. Therefore, this $\mathrm{Al}_{0.27} \mathrm{Ga}_{0.73}$ As layer forms a shell layer surrounding the core GaAs nanowire. Fig. 18(b) shows the FESEM image of core/shell GaAs/AlGaAs heterostructure nanowires. This class of nanowire structure might be useful for surface-emitting nanowire lasers.

It is predicted that freestanding III-V nanowires with high crystallographic perfection can be grown even on highly latticemismatched substrates due to radial expansion/contraction of the lattice constant. Indeed, successful fabrication of III-V nanowires on $\mathrm{Si} / \mathrm{Ge}$ substrates has been demonstrated [79]. Though there are large thermal, chemical, and structural mismatches between two highly dissimilar materials, high crystallographic and optical quality has been reported [80]. Fig. 19 shows the FESEM image of our InAs nanowires grown on GaAs ( $\left.\begin{array}{lll}1 & 1 & 1\end{array}\right)$ B substrate. Despite large mismatch of 7.2\%, InAs nanowires are successfully grown and their crystallographic

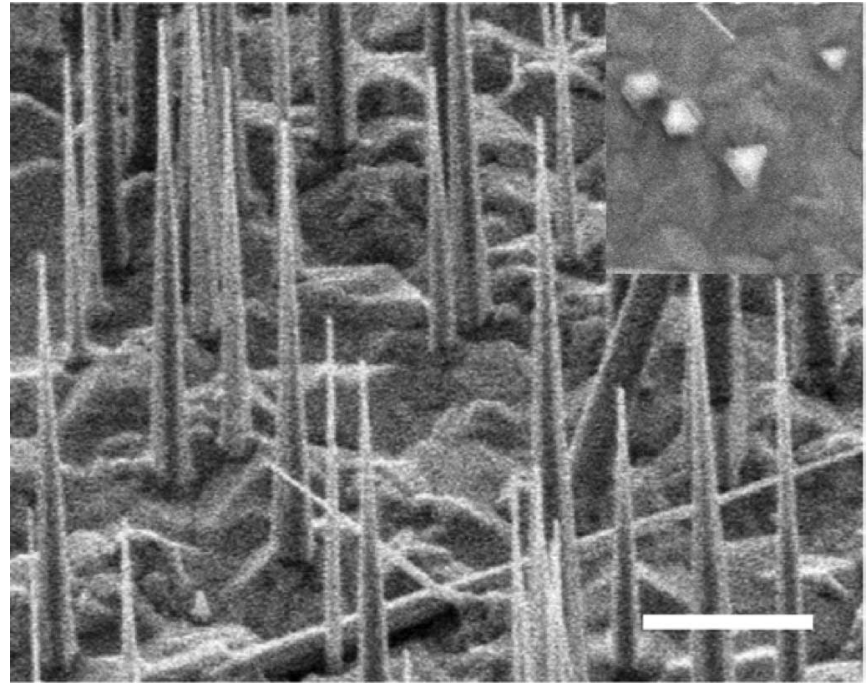

Fig. 19. $45^{\circ}$ tilted FESEM image of InAs nanowires on GaAs $\left(\begin{array}{lll}1 & 1 & 1\end{array}\right)$ B substrate. The inset shows the top view. Scale bar is $1 \mu \mathrm{m}$.

properties can be confirmed from hexagonal/triangular cross sections as shown in the inset. However, irregular substrate surface due to InAs 2-D growth can also be observed. This 2-D growth affects the nanowire growth and leads to nanowire height nonuniformity. In addition, a large tapering of InAs nanowire is observed due to highly mobile In reaction species on the (lll 111$)$ B surface.

\section{CONCLUSION}

We have investigated the effects of the main MOCVD growth parameters on QD formation. Each has a large impact on the nucleation process and needs to be carefully chosen in order to achieve device-quality QDs. SAE results also showed that the bandgap of these $\operatorname{In}(\mathrm{Ga})$ As QDs can be selectively tuned to have different bandgaps in different regions of the same substrate that is promising for integrated devices. These $\operatorname{In}(\mathrm{Ga})$ As QDs have been successfully incorporated into both diode lasers and infrared photodetectors, with good device performance. A maximum peak detectivity of $1.6 \times 10^{9} \mathrm{~cm} \cdot \mathrm{Hz}^{1 / 2} / \mathrm{W}$ was measured for 15 -stacked infrared photodetectors, close to that reported for MBE-grown devices of similar structure, while the fivestacked QD lasers showed ground state lasing for cavity lengths of $1.2 \mathrm{~mm}$. Finally, the growth GaAs and InAs nanowires and core/shell GaAs/AlGaAs heterostructure nanowires have been demonstrated and they look promising for nanoscale devices.

\section{REFERENCES}

[1] G. Park, O. B. Shchekin, D. Huffaker, and D. G. Deppe, "Low-threshold oxide-confined $1.3 \mu \mathrm{m}$ quantum-dot laser," IEEE Photon. Technol. Lett., vol. 12, no. 3, pp. 230-232, Mar. 2000.

[2] N. N. Ledentsov, M. Grundmann, F. Heinrichsdorff, D. Bimberg, V. M. Ustinov, A. E. Zhukov, M. V. Maximov, Zh. I. Alferov, and J. A. Lott, "Quantum-dot heterostructure lasers," IEEE J. Sel. Topics Quantum Electron., vol. 6, no. 3, pp. 439-451, May-Jun. 2000.

[3] R. L. Sellin, C. Ribbat, M. Grundmann, N. N. Ledentsov, and D. Bimberg, "Close-to-ideal device characteristics of high-power InGaAs/GaAs quantum dot lasers," Appl. Phys. Lett., vol. 78, no. 9, pp. 1207-1209, Feb. 2001. 
[4] J. Tatebayashi, N. Hatori, H. Kakuma, H. Ebe, H. Sudo, A. Kuramata, Y. Nakata, M. Sugawara, and Y. Arakawa, "Low threshold current operation of self-assembled InAs/GaAs quantum dot lasers by metal organic chemical vapour deposition," IEEE Electron. Lett., vol. 39, no. 15, pp. 1130-1131, Jul. 2003.

[5] X. Duan, Y. Huang, R. Agarwal, and C. M. Lieber, "Single-nanowire electrically driven lasers," Nature, vol. 421, pp. 241-245, 2003.

[6] M. T. Bjork, B. J. Ohlsson, C. Thelander, A. I. Persson, K. Deppert, L. R. Wallenberg, and L. Samuelson, "Nanowire resonant tunnelling diodes," Appl. Phys. Lett., vol. 81, pp. 4458-4460, 2002.

[7] C. Thelander, H. A. Nilsson, L. E. Jensen, and L. Samuelson, "Nanowire single-electron memory," Nano Lett., vol. 4, pp. 1987-1991, 2005.

[8] V. A. Shchukin, N. N. Ledentsov, and D. Bimberg, Epitaxy of Nanostructures. Berlin, Germany: Springer-Verlag, 2004.

[9] T. Pearsall, Ed., Quantum Semiconductor Devices and Technologies. Norwell, MA: Kluwer, 2000.

[10] P. Lever, "Interdiffusion and metal organic vapour phase epitaxial growth of self-assembled InGaAs quantum dot structures and devices" Ph.D. dissertation, Australian Nat. Univ., Canberra, Australia, Apr. 2004.

[11] R. Leon and S. Fafard, "Structural and radiative evolution in quantum dots near the InxGa1-xAs/GaAs Stranski-Krastanow transformation," Phys. Rev. B, Condens. Matter, vol. 58, no. 4, pp. R1726-R1729, 1998.

[12] K. Sears, H. H. Tan, J. Wong-Leung, and C. Jagadish, "The role of arsine in the self-assembled growth of InAs/GaAs quantum dots by metal organic chemical vapor deposition," Appl. Phys. Lett., vol. 99, p. 044908, 2006.

[13] D. Leonard, K. Pond, and P. Petroff, "Critical layer thickness for selfassembled InAs islands on GaAs," Phys. Rev. B, Condens. Matter, vol. 50, no. 16, pp. 11687-11692, 1994.

[14] A. Bhatti, M. G. Alessi, M. Capizzi, P. Frigeri, and S. Franchi, "Optical spectroscopy of quasi-monolayer InAs at the onset of quantum-dot nucleation," Phys. Rev. B, Condens. Matter, vol. 60, no. 4, pp. 2592-2598, 1999.

[15] F. Heinrichsdorff, A. Krost, M. Grundmann, D. Bimberg, F. Bertram, J. Christen, A. Kosogov, and P. Werner, "Self-organization phenomena of InGaAs/GaAs quantum dots grown by metal organic chemical vapour deposition," J. Cryst. Growth, vol. 170, no. 1-4, pp. 568-573, 1997.

[16] F. Heinrichsdorff, A. Krost, D. Bimberg, A. O. Kosogov, and P. Werner, "Self-organized defect free InAs/GaAs and InAs/InGaAs/GaAs quantum dots with high lateral density grown by MOCVD," Appl. Surf. Sci., vol. 123-124, pp. 725-728, 1998.

[17] E. Steimetz, W. Richter, F. Schienle, D. Fischer, M. Klein, and J.-T. Zettler, "The effect of different group V precursors on the evolution of quantum dots monitored by optical in situ measurements," Jpn. J. Appl. Phys., vol. 37, pp. 1483-1486, 1997.

[18] T. Chung, G. Walter, and N. Holonyak, Jr., "Growth mechanism of InAs quantum dots on GaAs by metal-organic chemical-vapor deposition," $J$. Appl. Phys., vol. 97, pp. 53510-53514, 2005.

[19] K. Sears, J. Wong-Leung, M. Buda, H. H. Tan, and C. Jagadish, "Growth and characterisation of InAs/GaAs quantum dots grown by MOCVD," in Proc. 2004 Conf. Optoelectron. Microelectron. Mater. Devices. Piscataway, NJ: IEEE Press, 2005, pp. 1-4.

[20] G. B. Stringfellow, Organometallic Vapor-Phase Epitaxy, 2nd ed. San Diego, CA: Academic, 1999.

[21] L. Chu, M. Arzberger, G. Boehm, and G. Abstreiter, "Influence of growth conditions on the photoluminescence of self-assembled InAs/GaAs quantum dots," J. Appl. Phys., vol. 85, pp. 2355-2362, 1999.

[22] P. Chen, Q. Xie, A. Madhukar, L. Chen, and A. Konkar, "Mechanisms of strained island formation in molecular-beam epitaxy of InAs on GaAs (100)," J. Vac. Sci. Technol. B, Microelectron. Process. Phenom., vol. 12, pp. 2568-2573, 1994.

[23] F. Heinrichsdorff, A. Krost, N. Kirstaedter, M.-H. Mao, M. Grundmann, D. Bimberg, A. Kosogov, and P. Werner, "InAs/GaAs quantum dots grown by metal organic chemical vapor deposition," Jpn.J. Appl. Phys., vol. 36, pp. 4129-4133, 1997.

[24] D. Westwood, Z. Sobiesierski, C. C. Matthai, E. Steimetz, T. Zettler, and W. Richter, "Processes of quantum dot formation in the InAs on GaAs (001) system: A reflectance anisotropy spectroscopy study," J. Vac. Sci. Technol. B, Microelectron. Process. Phenom., vol. 16, no. 4, pp. 2358 2366, 1998.

[25] T. I. Kamins, G. Medeiros-Ribeiro, D. A. Ohlberg, and R. S. Williams, "Evolution of Ge islands on Si (001) during annealing," J. Appl. Phys., vol. 85, pp. 1159-1171, 1999.

[26] K. Pötschke, L. Müller-Kirsch, R. Heitz, R. L. Sellin, U. W. Pohl, D. Bimberg, N. Zakharov, and P. Werner, "Ripening of self-organized InAs quantum dots," Physica E, vol. 21, pp. 606-610, 2004.
[27] H. Lee, R. Lowe-Webb, W. Yang, and P. Sercel, "Formation of InAs/GaAs quantum dots by molecular beam epitaxy: Reversibility of the islanding transition," Appl. Phys. Lett., vol. 71, pp. 2325-2327. 1997.

[28] R. M. Lammert, T. M. Cockerill, D. V. Forbes, and J. J. Coleman, "Dualchannel strained-layer in GaAs-GaAs-AlGaAs WDM source with integrated coupler by selective-area MOCVD," IEEE Photon. Technol. Lett., vol. 6, no. 10, pp. 1167-1169, Oct. 1994.

[29] M. L. Osowski, T. M. Cockerill, R. M. Lammert, D. V. Forbes D. E. Ackley, and J. J. Coleman, "A strained-layer InGaAs-GaAs-AlGaAs single quantum well broad spectrum LED by selective-area metalorganic chemical vapor deposition," IEEE Photon. Technol. Lett., vol. 6, no. 11 , pp. 1289-1291, Nov. 1994.

[30] R. M. Lammert, S. D. Roh, J. S. Hughes, M. L. Osowski, and J. J. Coleman, "MQW DBR lasers with monolithically integrated external-cavity electroabsorption modulators fabricated without modification of the active region," IEEE Photon. Technol. Lett., vol. 9, no. 5, pp. 566-568, May 1997.

[31] S. Mokkapati, P. Lever, H. H. Tan, C. Jagadish, K. E. McBean, and M. R. Phillips, "Controlling the properties of InGaAs quantum dots by selective-area epitaxy," Appl. Phys. Lett., vol. 86, pp. 113102-1-3, 2005 .

[32] Y. Arakawa and H. Sakaki, "Multidimensional quantum well laser and temperature dependence of its threshold current," Appl. Phys. Lett., vol. 40, no. 11, pp. 939-941, 1982.

[33] M. Asada, Y. Miyamoto, and Y. Suematsu, "Gain and the threshold of three dimensional quantum-box lasers," IEEE J. Quantum Electron., vol. 22, no. 9, pp. 1915-1921, Sep. 1986.

[34] G. T. Liu, H. Li Stintz, T. C. Newell, A. L. Gray, P. M. Varangis, K. J. Malloy, and L. F. Lester, "The influence of quantum-well composition on the performance of quantum dot lasers using InAs/InGaAs dots-in-a-well (DWELL) structures," IEEE J. Quantum Electron, vol. 36, no. 11 , pp. 1272-1279, 2000

[35] I. R. Sellers, H. Y. Liu, K. M. Groom, D. T. Childs, D. Robbins, T. J. Badcock, M. Hopkinson, D. J. Mowbray, and M. S. Skolnick, "1.3 $\mu \mathrm{m}$ InAs/GaAs multilayer quantum-dot laser with extremely low roomtemperature threshold current density," Electron. Lett., vol. 40, no. 22, pp. 1412-1413, Nov. 2004.

[36] A. R. Kovsh, N. A. Maleev, A. E. Zhukov, S. S. Mikhrin, A. P. Vasil'ev, Y. M. Shernyakov, M. V. Maximov, D. A. Livshits, V. M. Ustinov, Zh. I. Alferov, N. N. Ledentsov, and D. Bimberg, "InAs/InGaAs/GaAs quantum dot lasers of $1.3 \mu \mathrm{m}$ range with high $(88 \%)$ differential efficiency," Electron. Lett., vol. 38, no. 19, pp. 1104-1106, 2002.

[37] O. B. Shchekin and D. G. Deppe, " $1.3 \mu \mathrm{m}$ quantum dot laser with $T_{\mathrm{o}}=$ $161 \mathrm{~K}$ from 0 to $80^{\circ} \mathrm{C}$," Appl. Phys. Lett., vol. 80, no. 18, pp. 3277-3279, 2002.

[38] M. V. Maximov, I. V. Kochnev, Y. M. Shernyakov, S. V. Zaitsev, N. Y. Gordeev, A. F. Tsatsul'nikov, A. V. Sakharov, I. L. Krestnikov, P. S. Kop'ev, Z. I. Alferov, N. N. Ledentsov, D. Bimberg, A. O. Kosogov, P. Werner, and U. Gosele, "InGaAs/GaAs quantum dot lasers with ultrahigh characteristic temperature $\left(T_{\mathrm{O}}=385 \mathrm{~K}\right)$ grown by metal organic chemical vapour deposition," Jpn.J. Appl. Phys., vol. 36, no. 6B, pp. 4221-4223, 1997.

[39] A. E. Zhukov, A. R. Kovsh, V. M. Ustinov, Y. M. Shernyakov, S. S. Mikhrin, N. A. Maleev, E. Y. Kondrat'eva, D. A. Livshits, M. V. Maximov, B. V. Volovik, D. A. Bedarev, Y. G. Musikhin, N. N. Ledentsov, P. S. Kop'ev, Z. I. Alferov, and D. Bimberg, "Continuouswave operation of long-wavelength quantum-dot diode laser on a GaAs substrate," IEEE Photon. Technol. Lett., vol. 11, no. 11, pp. 1345-1347, Nov. 1999.

[40] H. Shoji, Y. Nakata, K. Mukai, Y. Sugiyama, M. Sugawara, N. Yokoyama, and H. Ishikawa, "Lasing characteristics of self-formed quantum-dot lasers with multistacked dot layer," IEEE J. Sel. Topics Quantum Electron., vol. 3, no. 2, pp. 188-195, Apr. 1997.

[41] V. M. Ustinov, A. E. Zhukov, A. Y. Egorov, and N. A. Maleev, Quantum Dot Lasers, 1st ed. Oxford, U.K.: Oxford Science, 2003.

[42] G. Park, O. B. Shchekin, and D. G. Deppe, "Temperature dependence of gain saturation in multilevel quantum dot lasers," IEEE J. Quantum Electron., vol. 36, no. 9, pp. 1065-1071, Sep. 2000.

[43] A. E. Zhukov, A. R. Kovsh, V. M. Ustinov, N. N. Ledentsov, A. F. Tsatsul'nikov, M. V. Maximov, Y. M. Shernyakov, V. I. Kopchatov, A. V. Lunev, P. S. Kop'ev, D. Bimberg, and Z. I. Alferov, "Gain characteristics of quantum dot injection lasers," Semicond. Sci. Technol., vol. 14, pp. 118-123, 1999. 
[44] O. G. Schmidt, N. Kirstaedter, N. N. Ledentsov, M.-H. Mao, D. Bimberg, V. M. Maximov, P. S. Kop'ev, and Z. I. Alferov, "Prevention of gain saturation by multi-layer quantum dot lasers," Electron. Lett., vol. 32, no. 14 , pp. 1302-1303, 1996.

[45] M. Buda, J. Hay, H. H. Tan, J. Wong-Leung, and C. Jagadish, "Low loss, thin p-clad $980 \mathrm{~nm}$ InGaAs semiconductor laser diodes with an asymmetric structure design," IEEE J. Quantum Electron., vol. 39, no. 5, pp. 625-633, May 2003.

[46] P. Lever, M. Buda, H. H. Tan, and C. Jagadish, "Characteristics of MOVPE grown InGaAs quantum dot lasers," Photon. Technol. Lett., vol. 16, pp. 2589-2591, 2004.

[47] — "Investigation of the blueshift seen in electroluminescence from MOCVD grown InGaAs QDs," IEEE J. Quantum Electron., vol. 40, no. 10, pp. 1410-1416, Oct. 2004.

[48] A. Passaseo, M. D. Vittorio, M. Todaro, I. Tarantini, M. D. Giorgi, R. Cingolani, A. Taurino, M. Catalano, A. Fiore, A. Markus, J. X. Chen, C. Paranthoen, U. Oesterle, and M. Ilegems, "Comparison of radiative and structural properties of $1.3 \mu \mathrm{m} \mathrm{In}_{x} \mathrm{Ga}_{1-x}$ As quantum dot laser structures grown by metal organic chemical vapor deposition and molecular beam epitaxy," Appl. Phys. Lett., vol. 82, no. 21, pp. 3632-3634, 2003.

[49] P. W. Fry, I. E. Itskevich, D. J. Mowbray, M. S. Skolnick, J. J. Finley, J. A. Barker, E. P. O'Reilly, L. R. Wilson, I. A. Larkin, P. A. Maksym, M. Hopkinson, M. Al-Khafaji, J. P. R. David, A. G. Cullis, G. Hill, and J. C. Clark, "Inverted electron-hole alignment in InAs-GaAs selfassembled quantum dots," Phys. Rev. Lett., vol. 84, no. 4, pp. 733-736, 2000

[50] W. Sheng and J.-P. Leburton, "Absence of correlation between built-in electric dipole moment and quantum stark effect in single InAs/GaAs self-assembled quantum dots," Phys. Rev. B, Condens. Matter, vol. 67 , pp. 125308-125311, 2003

[51] K. Sears, M. Buda, H. H. Tan, and C. Jagadish, "Modeling and characterization of InAs/GaAs quantum dot lasers grown by metal organic chemical vapor deposition," J. Appl. Phys., to be published.

[52] D. Pan, E. Towe, and S. Kennerly, "Normal-incidence intersubband (In,Ga)As/GaAs quantum dot infrared photodetectors," Appl. Phys. Lett., vol. 73, pp. 1937-1939, 1998.

[53] A. D. Stiff, S. Krishna, P. Bhattacharya, and S. W. Kennerly, "Normalincidence, high-temperature, mid-infrared, InAs-GaAs vertical quantumdot infrared photodetector," IEEE J. Quantum Electron., vol. 37, no. 11, pp. 1412-1419, Nov. 2001

[54] , "High-detectivity, normal-incidence, mid-infrared (1 4 $4 \mathrm{~m})$ InAs/GaAs quantum-dot detector operation at $150 \mathrm{~K}$," Appl. Phys. Lett., vol. 79, pp. 421-423, 2001.

[55] Z. Ye, J. C. Campbell, Z. H. Chen, E.-T. Kim, and A. Madhukar, "InAs quantum dot infrared photodetectors with In0.15Ga0.85As strain-relief cap layers," J. Appl. Phys., vol. 92, pp. 7462-7468, 2002.

[56] S. Raghavan, D. Forman, P. Hill, N. R. Weisse-Bernstein, G. V. Winckel, P. Rotella, S. Krishna, S. W. Kennerly, and J. W. Little, "Normal-incidence InAs/In0.15Ga0.85As quantum dots-in-a-well detector operating in the long-wave infrared atmospheric window $(8-12 \mu \mathrm{m}), " J$. Appl. Phys., vol. 96, pp. 1036-1038, 2004.

[57] B. F. Levine, "Quantum-well infrared photodetectors," J. Appl. Phys., vol. 74, pp. R1-R81, 1993.

[58] V. Ryzhii, "The theory of quantum-dot infrared phototransistors," Semicond. Sci. Technol., vol. 11, pp. 759-765, 1996.

[59] J. Phillips, "Evaluation of the fundamental properties of quantum dot infrared detectors," J. Appl. Phys., vol. 91, pp. 4590-4594, 2002.

[60] L. D. Moldavskaya, V. I. Shashkin, M. N. Drozdov, Y. N. Drozdov, V. M. Daniltsev, A. V. Murel, B. A. Andreev, A. N. Yablonsky, S. A. Gusev, D. M. Gaponova, O. I. Khrykin, A. Y. Luk'yanov, and E. N. Sadova, "Infrared lateral photoconductivity of InGaAs quantum dot heterostructures grown by MOCVD," Physica E, vol. 17, pp. 634-655, 2003.

[61] M. P. Pires, S. M. Landi, C. V.-B. Tribuzy, L. A. Nunes, E. Marega, and P. L. Souza, "InAs quantum dots over InGaAs for infrared photodetectors," J. Cryst. Growth, vol. 272, pp. 192-197, 2004.

[62] S. Kim, H. Mohseni, M. Erdtmann, E. Michel, C. Jelen, and M. Razeghi, "Growth and characterization of InGaAs/InGaP quantum dots for midinfrared photoconductive detector," Appl. Phys. Lett., vol. 73, pp. 963-965, 1998.

[63] J. Jiang, S. Tsao, T. O’Sullivan, W. Zhang, H. Lim, T. Sills, K. Mi, M. Razeghi, G. J. Brown, and M. Z. Tidrow, "High detectivity In$\mathrm{GaAs} / \mathrm{InGaP}$ quantum-dot infrared photodetectors grown by low pressure metal organic chemical vapor deposition," Appl. Phys. Lett., vol. 84, pp. 2166-2168, 2004
[64] J. Jiang, K. Mi, S. Tsao, W. Zhang, H. Lim, T. O'Sullivan, T. Sills, M. Razeghi, G. J. Brown, and M. Z. Tidrow, "Demonstration of a $256 \times$ 256 middle-wavelength infrared focal plane array based on InGaAs/InGaP quantum dot infrared photodetectors," Appl.Phys. Lett., vol. 84, pp. 2232 $2234,2004$.

[65] L. Fu, P. Lever, K. Sears, H. H. Tan, and C. Jagadish, "In0.5Ga0.5As/GaAs quantum dot infrared photodetectors grown by metal-organic chemical vapor deposition," IEEE Electron Device Lett., vol. 26, no. 9, pp. 628630, Sep. 2005.

[66] L. Fu, H. H. Tan, I. McKerracher, J. Wong-Leung, C. Jagadish, N. Vukmirović, and P. Harrison, "Effect of rapid thermal annealing on device characteristics of InGaAs/GaAs quantum dot infrared photodetectors," $J$. Appl. Phys., vol. 99, no. 11, pp. 114517-1-114517-8, 2006.

[67] Z. H. Chen, O. Baklenov, E. T. Kim, I. Mukhametzhanov, J. Tie, A. Madhukar, Z. Ye, and J. C. Campbell, "Normal incidence InAs/ $\mathrm{Al}_{x} \mathrm{Ga}_{1-x}$ As quantum dot infrared photodetectors with undoped active region," J. Appl. Phys., vol. 89, pp. 4558-4563, 2001

[68] S.-T. Chou, S.-Y. Lin, R.-S. Hsiao, J.-Y. Chi, J.-S. Wang, M.-C. Wu, and J.-F. Chen, "High-performance 30-period quantum-dot infrared photodetector," J. Vac. Sci.Technol. B, Microelectron. Process. Phenom., vol. 23 , pp. 1129-1131, 2005.

[69] S. Chakrabarti, A. D. Stiff-Roberts, P. Bhattacharya, S. Gunapala S. Bandara, S. B. Rafol, and S. W. Kennerly, "High-temperature operation of InAs-GaAs quantum-dot infrared photodetectors with large responsivity and detectivity," IEEE Photon. Technol. Lett., vol. 16, no. 5, pp. 1361-1363, May 2004.

[70] R. S. Wagner and W. C. Ellis, "Vapor-liquid-solid mechanism of single crystal growth," Appl. Phys. Lett., vol. 4, pp. 89-90, 1964.

[71] E. I. Givargizov, "Fundamental aspects of VLS growth," J. Cryst. Growth, vol. 31, pp. 20-30, 1975.

[72] K. Hiruma, M. Yazawa, K. Haraguchi, K. Ogawa, T. Katsuyama, M. Koguchi, and H. Kakibayashi, "GaAs free-standing quantum-size wires," J. Appl. Phys., vol. 74, pp. 3162-3171, 1993.

[73] C. M. Lieber, "Nanoscale science and technology: Building a big future from small things," Mater. Res. Soc. Bull., vol. 28, pp. 486-491, 2003.

[74] M. H. Huang, S. Mao, H. Feick, H. Yan, Y. Wu, H. Kind, E. Weber, R. Russo, and P. Yang, "Room-temperature ultraviolet nanowire nanolasers," Science, vol. 292, pp. 1897-1899, 2001.

[75] A. I. Persson, M. W. Larsson, S. Stenstrom, B. J. Ohlsson, L. Samuelson, and L. R. Wallenberg, "Solid-phase diffusion mechanism for GaAs nanowire growth," Nat. Mater., vol. 3, pp. 677-668, 2004.

[76] L. Schubert, P. Werner, N. D. Zakharov, G. Gerth, F. M. Kolb, L. Long, U. Gosele, and T. Y. Tan, "Silicon nanowhiskers grown on $\langle 111\rangle$ Si substrate by molecular-beam epitaxy," Appl. Phys. Lett., vol. 84, pp. 49684970, 2004.

[77] W. Seifert, M. Borgstrom, K. Deppert, K. A. Dick, J. Johansson, M. W. Larsson, T. Martensson, N. Skold, C. P. T. Svensson, B. A. Wacaser, L. R. Wallenberg, and L. Samuelson, "Growth of one-dimensional nanostructures in MOVPE," J. Cryst. Growth, vol. 272, pp. 211-220, 2004.

[78] Y. Kim, H. J. Joyce, Q. Gao, H. H. Tan, C. Jagadish, M. Paladugu, J. Zin, and A. A. Suvorova, "Influence of nanowire density on the shape and optical properties of ternary InGaAs nanowires," Nano Lett., vol. 6 pp. 599-604, 2006.

[79] E. P. A. M. Bakkers, J. A. Van Dam, S. D. Franceschi, L. P. Kouwenhoven, M. Kaiser, M. Verheijen, H. Wondergem, and P. van der Sluis, "Epitaxial growth of InP nanowires on germanium," Nat. Mater, vol. 3, pp. 769-773, 2004.

[80] T. Martensson, C. P. T. Svensson, B. A. Wacaser, M. W. Larsson, W. Seifert, K. Deppert, A. Gustafsson, L. R. Wallenberg, and L. Samuelson, "Epitaxial III-V nanowires on silicon," Nano Lett., vol. 4, pp. 1987-1990, 2004

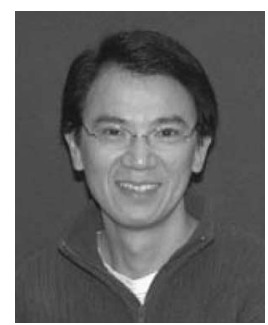

H. H. Tan (S'93-M'96-SM'03) received the B.E. (Hons.) degree in electrical engineering from the University of Melbourne, Melbourne, Australia, and the $\mathrm{Ph} . \mathrm{D}$. degree in electronic materials from the Australian National University, Canberra, Australia, in 1992 and 1997, respectively.

Currently, he is a Research Fellow in the Department of Electronic Materials Engineering, Australian National University. He is the author or coauthor of more than 100 research papers published in international journals and is the author of a book chapter on quantum well intermixing. He is the holder of several patents in quantum well 
infrared photodetectors and laser diodes. His current research interests include epitaxial growth of low-dimensional III-V semiconductors, ion implantation processing of III-V multilayer semiconductors, and fabrication of novel optoelectronic devices.

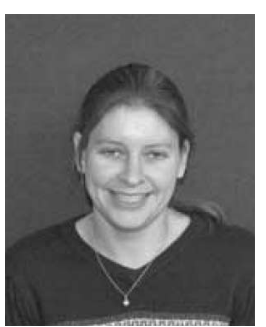

K. Sears (S'02) received the B.Sc./B.E. (Hons.) degree in physics and interdisciplinary systems engineering in 2000 from the Australian National University, Canberra, Australia, where she is currently working toward the Ph.D. degree.

She was with Redfern Integrated Optics, Sydney, Australia. Her current research interests include growth of InAs/GaAs quantum dots by metal-organic vapor epitaxy and their application to diode lasers and infrared detectors.

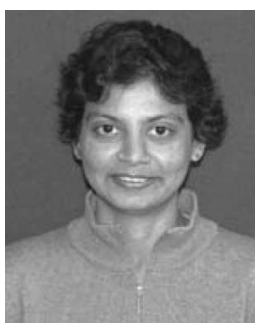

S. Mokkapati (S'03) was born in India. She received the M.Sc. degree in physics in 1999 and the M.Tech degree in materials science in 2001 from the University of Hyderabad, Hyderabad, India and the Indian Institute of Technology, Kanpur, India, respectively. Currently, she is working toward the Ph.D. degree at the Department of Electronic Materials Engineering, Australian National University, Canberra, Australia.

Her current research interests include p-doped quantum dot lasers and selective area metal-organic chemical-vapor deposition for integration of photonic devices.

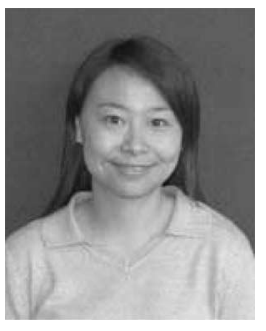

Lan Fu (S'99-A'01-M'03) received the B.E. degree in electrical engineering from the Hefei University of Technology, Hefei, China, and the M.S. degree in solid state physics from the University of Science and Technology of China, Hefei, in 1993 and 1996, respectively. She received the Ph.D. degree in electronic materials from the Australian National University, Canberra, Australia, in 2001, for research on quantum well intermixing in (In) GaAs/GaAs materials and devices.

Currrently, she is a Research Fellow in the Department of Electronic Materials Engineering, Australian National University. Her research interests include metal-organic chemical-vapor deposition growth of III-V semiconductor materials, and design, fabrication, and integration of optoelectronic devices.

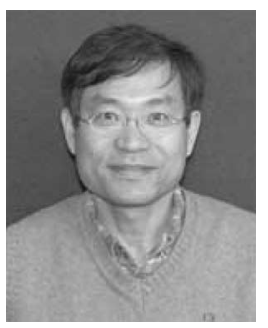

Yong Kim was born in Seoul, Korea, on April 8, 1961. He received the B.S. degree from Seoul National University, Seoul, in 1983, and the M.S. and Ph.D. degrees from the Korea Advanced Institute of Science and Technology, Daejeon, Korea, in 1985 and 1991, respectively, all in physics.

From 1985 to 1995 , he was a Senior Research Scientist at the Korea Institute of Science and Technology, Seoul, where he was engaged in research on the epitaxial growth of III-V compound semiconductor structure by metal-organic chemical vapor deposition. From 1995 to 1996, he was an Australian Research Council International Fellow at the Australian National University, Canberra, Australia. In 1999, he joined Dong-A University, Busan, Korea, where he is currently a Professor in the Department of Physics. His current research interests include the realization of III-V nanowires via very large scale growth mechanism for photonic device applications.

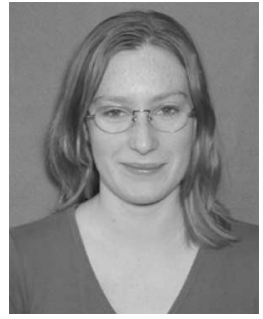

P. McGowan (S'98-M'04) received the B. E (Hons.) degree from the Department of Electrical and Computer Engineering, University of Canterbury, Christchurch, New Zealand, in 2000. She received the $\mathrm{Ph} . \mathrm{D}$. degree in electronic materials from the Australian National University, Canberra, Australia, in 2005, for metal-organic chemical vapor deposition growth and interdiffusion of InGaAs quantum dot structures and devices. U.K

Currently, she is with TTPCom Ltd., Cambridge,

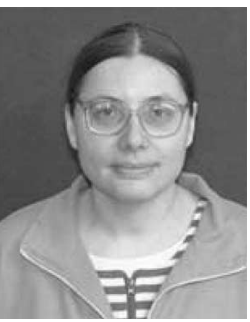

M. Buda received the B.E. degree in solid state physics from the University of Bucharest, Bucharest, Romania, in 1984, and the Ph.D. degree in electronics engineering from the Technical University of Eindhoven, Eindhoven, The Netherlands, in 1999.

She was a Research Fellow in the Department of Electronic Materials Engineering, Australian National University, Canberra, Australia. Currently, she is with the National Institute of Material Physics, Bucharest, Romania, where she is involved in the study of high- $k$ dielectrics and chalcogenide semiconductors. Her current research interests include special semiconductor laser diodes.

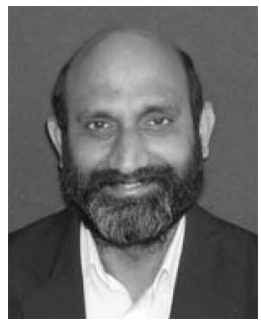

Chennupati Jagadish (S'84-M'86-SM'92-F'02) received the B.Sc. degree in physics from Nagarjuna University, Guntur, India, in 1977, the M.Sc.(Tech.) degree from Andhra University, Waltair, India, in 1980 , and the M.Phil. degree in applied physicselectronics and Ph.D. degree in physics from the University of Delhi, Delhi, India, in 1982 and 1986, respectively.

From 1985 to 1988, he was a Lecturer in Physics and Electronics at S.V. College, University of Delhi. From 1988 to 1990, he was a Research Associate at Queen's University, Kingston, ON, Canada. Currently, he is a Federation Fellow, Professor, and Head of Semiconductor Optoelectronics and Nanotechnology Group, Department of Electronic Materials Engineering, Research School of Physical Sciences and Engineering, Australian National University, Canberra, Australia. He is the author of more than 310 research papers published in international journals. He has coauthored a book, coedited a book, and coedited seven conference proceedings. His current research interests include compound semiconductor optoelectronics and nanotechnology.

Dr. Jagadish is a Fellow of the American Physical Society, the Optical Society of America (OSA), the Australian Institute of Physics, the Institute of Physics, U.K., the Institute of Nanotechnology, U.K., the International Society for Optical Engineering, the Electrochemical Society, the Australian Academy of Technological Sciences and Engineering, and the Australian Academy of Science. From 1999 to 2004, he served as an Elected Member of EDS AdCom. From 1998 to 2003, he was the Chair of the Optoelectronic Devices Technical Committee of the IEEE Electron Devices Society (EDS). During 1993-2005, he served as the Chair of the Australian Chapter of the EDS and the IEEE Lasers and Electro-Optics Society (LEOS). He is currently the Vice-President (Membership and Regional Activities-Asia Pacific) of LEOS and is the Chair of the Nano-Optoelectronics and Nano-Photonics Technical Committee of the IEEE Nanotechnology Council (NTC). He is serving on the IEEE Fellow Committee and is also the Chair of the NTC Awards Committee. He was the recipient of the 2000 IEEE Millennium Medal and served as a Distinguished Lecturer of both the LEOS and the EDS. During 2004 and 2005, he served as the Vice-President (Publications) of the NTC. He serves on the editorial boards of eight journals in addition to being an Associate Editor of the IEEE/OSA JOURNAL OF LIGHTWAVE TECHNOLOGY. 